\title{
A PLACE FOR NOUNS AND A PLACE FOR VERBS? \\ A CRITICAL REVIEW OF NEUROCOGNITIVE DATA ON GRAMMATICAL CLASS EFFECTS
}

Davide Crepaldi, Manuela Berlingeri, Eraldo Paulesu, and Claudio Luzzatti

Department of Psychology, University of Milano-Bicocca, Italy

RUNNING HEAD: Nouns and verbs in the brain

To appear in Brain and Language

Corresponding author:

Davide Crepaldi

Dipartimento di Psicologia, Università di Milano-Bicocca

piazza dell'Ateneo Nuovo 1

20126 Milano

Italy

E-mail: davide.crepaldi1@unimib.it

Phone (direct): +39 (0)2-64483840

Fax (departmental): +39 (0)2-64483706 


\begin{abstract}
It is generally held that noun processing is specifically sub-served by temporal areas, while the neural underpinnings of verb processing are located in the frontal lobe. However, this view is now challenged by a significant body of evidence accumulated over the years. Moreover, the results obtained so far on the neural implementation of noun and verb processing appear to be quite inconsistent. The present review briefly describes and critically re-considers the anatomo-correlative, neuroimaging, MEG, TMS and cortical stimulation studies on nouns and verbs with the aim of assessing the consistency of their results, particularly within technique. The paper also addresses the question as to whether the inconsistency of the data could be due to the variety of the tasks used. However, it emerged that neither the different investigation techniques used nor the different cognitive tasks employed fully explain the variability of the data. In the final section we thus suggest that the main reason for the emergence of inconsistent data in this field is that the cerebral circuits underlying noun and verb processing are not spatially segregated, at least for the spatial resolution currently used in most neuroimaging studies.
\end{abstract}

Keywords: nouns, verbs, grammatical class, functional independence, anatomical independence, fMRI, PET, anatomo-functional correlations, neural circuit. 


\section{Introduction}

Regardless of their communicative function (e.g., asking vs. affirming), all human linguistic acts have a core in which (i) a specific object is singled out (denoted) and (ii) a number of properties are attributed to this object (predicated; e.g., Chomsky, 1995). This basic communicational distinction between denotation and predication may be conceived as lexically reflected in the noun-verb dichotomy: elements in the former category naturally sub-serve denotation, while words belonging to the latter class naturally predicate the properties and relationships relative to what is denoted by nouns. Given that virtually all languages, with very few and controversial exceptions (e.g., Foley, 1998; Langacker, 1987; Robins, 1952), make a basic differentiation between nouns and verbs, it follows that these two parts of speech have a privileged status among grammatical classes.

A behavioural diagnostic of the privileged status of nouns and verbs can be found in the extensive neuropsychological literature reporting on aphasic patients with disproportionate impairment of either of these two grammatical classes. In a seminal paper, Holmes, Marshall and Newcombe (1971) described a dyslexic patient whose performance on nouns in a reading task was significantly better than on the verbs in the same task. This report was followed by many others (e.g., Miceli, Silveri, Villa, \& Caramazza, 1984; McCarty \& Warrington, 1985) and today noun-verb dissociation has been documented through several different tasks, i.e., writing to dictation (Rapp \& Caramazza, 2002), oral picture naming (Zingeser \& Berndt, 1988), written picture naming (Caramazza \& Hillis, 1991), word-to-picture matching (Hillis \& Caramazza, 1995) and spontaneous speech (Bastiaanse \& Jonkers, 1998; Crepaldi, Ingignoli, Verga, Contardi, Semenza, \& Luzzatti, in press). The range of aphasic syndromes associated with predominant impairment of either nouns or verbs is very wide; some verb-impaired patients suffer from fluent aphasia, others from non-fluent aphasia (see Luzzatti, Raggi, Zonca, Pistarini, Contardi, \& Pinna, 
2002); moreover, while some cases of dissociation emerged only in specific tasks (e.g., Berndt, Sloan, Mitchum, \& Heandiges, 1997a, 1997b) or even affected different grammatical classes in different tasks (Hillis \& Caramazza, 1995), other patients showed a very consistent pattern over different behavioural tasks (Berndt et al., 1997). This wide variety of patterns makes it plausible to assume that noun-verb dissociation can emerge as a consequence of different types of functional damage in different patients: indeed, it has been suggested that noun- and verb-specific impairment arises at lexical-phonological (e.g., Rapp \& Caramazza, 2002), lexical-syntactic (e.g., Crepaldi, Aggujaro, Arduino et al., 2006), semantic (e.g., Bird, Howard and Franklin, 2000) and syntactic levels (e.g., Friedmann, 2000). Whatever functional interpretation of the phenomenon is adopted (as suggested above, this might vary from patient to patient), the existence of a double dissociation in brain-damaged individuals unequivocally argues for separate and functionally independent representation for nouns and verbs. The question then arises as to whether functional independence is also anatomical, i.e., whether noun and verb processing is carried out by neural circuits involving spatially segregated brain areas. This issue will be addressed in the present paper by analysing the evidence provided so far by anatomo-correlative, neuroimaging, TMS and cortical stimulation studies.

Of course, noun and verb processing develops through a series of different computational stages (e.g., semantic processing, lexical retrieval, articulation or even lexical orthographic identification). As clearly shown by neuropsychological impairments and, more controversially, by neuroimaging research, these levels of processing are somewhat functionally independent (i.e., one or more levels can cease to function after brain damage or be spared, as the case may be) and might be based on different neural circuits (e.g., frontal damages typically cause syntactic and articulatory deficits, whereas lexical deficits normally arise after temporal damage). Therefore, the question of whether nouns and verbs are processed in brain areas that are spatially segregated must be 
addressed separately for each processing level (orthographic, phonological, lexical, syntactic, morphological, and semantic). Cognitive neuropsychology has shown functional independence between nouns and verbs at virtually all cognitive levels (due to the fact that patients have been shown to dissociate in several tasks); however, because functional independence does not always imply anatomical independence, different grammatical classes may recruit different brain areas at specific cognitive levels (e.g., lexical-semantic processing), but not at others (e.g., phonological encoding). In overt contrast with these considerations, noun and verb processing have been often treated as two monolithic entities in the literature, and this might be the reason why a very inconsistent picture emerges from previous studies (as we will document below). One the main aim of this review is to assess whether a more appropriate consideration of the cognitive level(s) addressed in each study contributes to clarify the results obtained so far, perhaps showing that nouns and verbs are spatially segregated at certain levels of processing, but overlap anatomically at some others.

\section{Anatomo-correlative studies on patients suffering from focal brain damage}

In a review conducted by Cappa and Perani (2003), the authors concluded that lexical retrieval deficits predominantly involving action naming mainly arise in patients with frontal (and, to a lesser extent, parietal) brain lesions, while noun-specific lexical impairments emerge after temporal lesions. However, as these authors freely acknowledge, this generalization appears to be flawed by several exceptions.

The fronto-temporal dichotomy hypothesis (FTDH) originated in a study by Damasio and Tranel (1993), where three brain-damaged individuals with an almost pure naming deficit were described: two patients had selective difficulties in retrieving nouns as opposed to verbs in a picture naming task, while one patient was impaired in retrieving verbs. The lesions characterizing the 
noun-impaired patients were limited to the temporal lobe and overlapped in the anterior mid- and inferior temporal regions, just behind the temporal pole. Quite significantly, one of the two noun-impaired patients could name tools much better than animals and fruits (quite as well as actions, in fact), so that his impairment appeared to be specific to natural objects rather than to nouns per se; a similar - even if less clear-cut - pattern also emerged in the second noun-impaired patient. The lesion characterizing the verb-impaired patient was located in the posterior segment of the left inferior frontal gyrus and the anterior segment of the left precentral gyrus.

Although several studies (e.g., Daniele, Giustolisi, Silveri, Colosimo, \& Gainotti, 1994) have shown results consistent with those reported in Damasio and Tranel (1993), a number of other papers have reported evidence against the FTDH. Aphasic patients have been described as suffering from verb impairment after lesions lying outside the left frontal regions (Silveri \& Di Betta, 1997; Silveri, Perri, \& Cappa, 2003), whereas verb retrieval was spared in other individuals, in spite of vast left prefrontal lesions. In particular, the patient described by De Renzi and Di Pellegrino (1995) had a very large left frontal lesion involving the frontal operculum and the premotor cortices in Brodmann area 6, and partially extending into the prefrontal region; nevertheless, he was still able to retrieve verbs both in picture naming and sentence completion tasks (he consistently named over $85 \%$ of the verbs correctly).

More recently, Aggujaro, Crepaldi, Pistarini, Taricco and Luzzatti (2006) found a more complex anatomical pattern in a study based on a large sample of verb-impaired aphasic patients. In their study, using a classical picture naming task, verb impairment emerged in four patients as a consequence of extensive left perisylvian damage involving virtually all the left hemisphere language areas and in other four patients suffering from a lesion limited to the posterior part of the left superior temporal gyrus at its junction with the left inferior parietal gyrus; finally, it was also present in another four aphasic patients after purely sub-cortical and insular damage. No patient 
with verb impairment was reported with a cerebral lesion that was limited to either the frontal or the parietal lobe.

Another wide sample of verb-impaired aphasic patients has been described by Tranel, Manzel, Asp, and Kemmerer (2008), who asked their patients to name short video clips representing actions. As in Aggujaro et al. (2006), different anatomical patterns emerged: nine patients had lesions overlapping in the left frontal operculum and the underlying white matter, while two other patients had lesions overlapping in the medio-temporal region and the occipito-temporal junction of the left hemisphere. Interestingly, among the 9 patients whose lesions maximally overlapped in the left frontal operculum, 4 also had non-negligible damage to the inferior parietal lobule.

Altogether, the FTDH seems to be overly simplistic, at least as far as verbs are concerned. No single brain area appears to be systematically associated with verb retrieval impairment, as would be expected if the neural circuitry responsible for verb processing was spatially concentrated in a specific cerebral region; similar conclusions were drawn in a recent review of anatomo-correlative studies on grammatical class effects (Mätzig, Druks, Masterson, \& Vigliocco, 2009). Particularly in the view of the most recent studies on a large number of patients (i.e., Aggujaro et al., 2006 and Tranel et al., 2008), we can fairly assume that verb retrieval is sub-served by a fronto-temporo-parietal network, which is mostly -- but not exclusively -- based in the frontal operculum and in the inferior parietal lobule; this circuitry most likely involves also a set of subcortical structures bridging the communication between the frontal and parietal areas. Moreover, in order to account for those who were spared at retrieving verbs in spite of having frontal or parietal lesions, it must be held that this network has a high degree of internal vicariousness, i.e., it can easily tolerate the loss of part of its structure, arguably because its sub-components can take over the role of other (damaged) sub-components; alternatively, one may assume a limited degree of sub-specialization within this network. 
With regard to the neural circuitry underlying noun production, the correlation between selective impairment for naming objects and lesions centred on the temporal lobe has received independent support (Glosser and Donofrio, 2001; Hillis, Tuffiash, Wityk, \& Barker, 2002). However, the picture is still far from being clear (e.g., Mätzig et al., 2009). In fact, in Glosser and Donofrio's study (2001) patients that underwent left anterior temporal lobectomy (LATL) were more impaired in naming objects than patients whose right anterior temporal lobe (RATL) was removed; however, LATL patients were more impaired than RATL on naming actions also, even though the difference was slightly less than in the object naming task. This gives rise to the possibility that the left anterior temporal lobe participates in verb production also, even though its role in noun retrieval may be more fundamental. Moreover, the temporal lesion in these patients seems to be more anterior than in Damasio and Tranel's (1993) patients. All noun-impaired patients considered in Aggujaro et al.'s study (2006) suffered from a temporal lesion; however, while the damage affected the central part of the mid and inferior temporal gyri in three patients, in other two patients it was limited to the temporo-occipital junction. It is worth noting that no noun-impaired patient included in this study suffered from an anterior temporal lesion analogous to that described by Glosser and Donofrio (2001).

Altogether, the anatomo-correlative studies on noun retrieval consistently report a role for temporal areas in object naming, but there is contrasting evidence as to which part of the temporal lobe underlies noun processing.

The functional level at which the noun-verb dissociation originated in the different patients is a factor that should be taken into consideration when interpreting the results of the anatomo-correlative literature. In fact, noun and verb processing may be selectively damaged at a phonological, orthographic, lexical, semantic or lexical-syntactic level, and thus brain areas that have been identified as responsible for noun and verb processing might differ across studies simply 
because they underlie different levels of linguistic processing. All the anatomo-correlative studies described above made use of picture naming tasks; the brain areas described in these studies are thus to be considered as housing noun- or verb-specific lexical-semantic processing, lemma selection and lexeme selection (see Levelt, Roelofs, and Meyer, 1999). The issue of the cognitive level at which noun and verb anatomical correlates are studied will be addressed more specifically while considering the neuroimaging literature; in these studies, in fact, the cognitive level of processing under investigation can be experimentally manipulated through the choice of a specific experimental and baseline task.

\section{Functional neuroimaging studies}

This section examines all the studies that (i) investigated the neurofunctional network underlying noun and verb processing in normal young adults and (ii) included both a noun and a verb condition.

The behavioural and anatomo-clinical evidence discussed above sets the rationale for functional neuroimaging (PET, fMRI and MEG) and transcranial magnetic stimulation (TMS) investigations of noun and verb processing in normal subjects: to date there are more or less forty papers reporting with these investigations in the peer reviewed literature.

As mentioned above, no clear picture emerges from this vast database and there is no consensus on an anatomical dissociation that may underpin the noun/verb dichotomy; a clear example of this is given in Berlingeri, Crepaldi, Roberti, Scialfa, Luzzatti, and Paulesu (2008). In Figure 1 the authors reported the noun-related and verb-related activations found in previous functional neuroimaging studies on a brain template. The result was a pattern of noun-related and verb-related activations distributed across cerebral regions and hemispheres, with no area exclusively associated with either nouns or verbs. 
There is a number of causes which may have contributed to generate such inconsistent results; some are well known factors that need to be taken into account when assessing imaging data from different experiments:

(a) the nature of the primary task: noun and verb processing may be elicited through printed or auditory stimuli and this inevitably determines the activation of certain regions rather than others due simply to the different input channels.

(b) The nature of the "experimental" component within the primary task: subjects may be required to make explicit judgements on specific questions - is "square" a noun or a verb? - or may be asked to generate one correct response (as in picture naming) or several different responses (as when they are required to think of as many verbs - or nouns - as possible in response to a given cue).

(c) The technique used (PET vs. fMRI vs. MEG), the sample size, the number of scans per subject (in PET and fMRI studies), the statistical approach adopted in the analyses of the data, and the threshold used to separate significant from non-significant voxels, all play a dramatic role in determining which areas are activated. Neglecting these factors may lead to erroneous conclusions.

(d) Finally, the choice of the baseline condition clearly plays an important role in determining seemingly different outcomes for the same experimental task (see Friston, 2005, and Newman, Twieg, \& Carpenter, 2001, for an in-depth consideration of this issue ${ }^{1}$ ).

\footnotetext{
${ }^{1}$ Newman and colleagues (2001) explicitly tested the role of different baselines (i.e., rest state, passive listening and task-related baseline) in determining different functional neuroimaging results with the same experimental task, the same material, and the same sample of participants. A certain degree of baseline-related variability in the results is intrinsic in the experimental designs based on subtractive logic (particularly those which included a baseline condition) and can only be
} 
All the considerations examined above clearly militate against a systematic and pedantic discussion of each and every peak of activation reported in the imaging studies on noun and verb processing, and also suggest that it makes little sense to compare results obtained in studies which use non-comparable experimental tasks and relatively remote baselines. In line with this argument,

(i) we will report the results obtained in simple effects (task vs. baseline) in the tables, without discussing them in depth into the text body; these activation peaks are in fact the most likely to be dominated by effects that are experiment-specific (i.e., the effect of the primary task), rather than by general grammatical class effects ${ }^{2}$.

(ii) we will consider the results of neuroimaging studies on nouns and verbs carried out using different experimental tasks separately: this should guarantee that the brain areas being compared underlie levels of cognitive processing (e.g., phonological, lexical, semantic) that are comparable, if not identical.

This procedure should make clear where we expect to observe consistent and replicable results across different studies, namely, (i) in direct comparisons between noun and verb scans across studies using the same (or very similar) experimental tasks, and (ii) in the interaction effects -

eliminated (or, at least, considerably reduced) by using methodologies such as parametric or factorial designs (e.g., Friston 2005). However, in the noun-verb literature, all fMRI and PET studies adopted a subtractive logic and only 3 out of 31 did not include a baseline condition.

${ }^{2}$ Because simple effects of nouns-minus-baseline and verbs-minus-baseline can be obtained also in experiments that investigate only one of the two grammatical classes, the tables also describe those studies that only included either a noun or a verb condition. We also imposed as a further inclusion criterion that the simple effect analysis was made against a baseline that clearly did not require either noun or verb processing. 
mainly between task and grammatical class - emerging in studies based on a factorial design.

Although it cannot be excluded that some spurious cross-experimental variability will affect the results obtained with this procedure, it still seems to constitute the best tool to address the issue of the anatomical independence of noun and verb processing, as it allows better control over the confounds due to the type of experimental task, the baseline and the statistical approach adopted. So, if a linguistic level of analysis (e.g., phonological, orthographic, lexical) exists where the neural circuits responsible for noun and verb processing are spatially segregated in the brain, we can expect to find consistent evidence of this segregation in the results of noun-verb direct comparison analyses and in the emergence of grammatical class-by-task interactions.

\subsection{Written lexical decision}

We will consider first the studies addressing the most peripheral aspects of lexical processing, i.e., those related to word recognition as investigated through lexical decision. The studies described in this paragraph tap on peripheral orthographic processing (letter identification and morpho-orthographic segmentation) and lexical identification. Linguistically speaking, there is little ground for anatomical segregation of nouns and verbs at this level of analysis, because the distinction between these classes is based on syntactic and semantics - rather than orthographic aspects. However, much psycholinguistic evidence indicates that lexical decision automatically recruits conceptual (e.g., Perea \& Rosa, 2002) and phonological processing (Rastle \& Brysbaert, 2006), thus rising expectations of different brain activations for nouns and verbs.

Perani, Cappa, Schnur et al. (1999) conducted a PET study where a written lexical decision task was compared to an orthographic detection task, in which the subjects had to decide whether a string contained an " $\mathrm{X}$ ". The direct comparisons between noun and verb scans revealed that nouns did not activate any brain area more than verbs did, while verbs activated a complex pattern of areas 
spanning all four lobes in the left hemisphere (see Table 1).

Quite different results were obtained by Tyler, Russell, Fadili and Moss (2001) using a very similar methodology (same experimental and control tasks and same neuroimaging technique, i.e., PET). Although Perani et al. (1999) and Tyler et al. (2001) both report that nouns did not activate any brain area to a greater extent than verbs (as revealed by the direct comparison between the two grammatical classes), only the right substantia nigra (and no single cortical area) emerged in the opposite direct contrast in Tyler et al.'s study (Table 1).

Lexical decision was also compared with an orthographic baseline in the experiments carried out in Japanese Katakana script by Fujimaki, Miyauchi, Putz et al. (1999) and Yokoyama, Miyamoto, Riera et al. (2006). In their very articulated experiment (see Table $1 \mathrm{~b}$ for more details about the several areas which emerged in the simple effect analysis), Fujimaki and colleagues found no evidence of differential results for nouns and verbs, with the exception of a higher activation for nouns bilaterally in the inferior parietal sulcus and in the precentral sulcus (Table 1b). According to the direct comparison analyses carried out by Yokoyama et al. (2006), no brain area was specifically associated with either nouns or verbs, although in a region-of-interest analysis the left mid temporal gyrus turned out to be more activated by both active and passive verbs than by nouns.

\section{TABLE 1 ABOUT HERE}

In two other studies, lexical decision was compared with passive viewing of a fixation point. In a study carried out in Chinese, Li, Jin and Tan (2004) found noun-specific activation in the caudate nucleus while analysing the direct comparison between nouns and verbs; on the contrary, no area emerged as being specifically activated by verb processing (Table 1). Thompson, Bonakdarpour, 
Fix et al. (2007) focused their attention on the neural correlates of verb argument structure processing and found no area to be specifically associated with either nouns or verbs in their direct comparison analyses (Table 1).

\subsubsection{Summary of the lexical decision literature on written stimuli}

Altogether, these results appear to be largely inconsistent. Verbs-minus-nouns direct comparisons vary strikingly across studies: some authors reported no activation at all (Yokoyama et al., 2006), others showed only sub-cortical activation (Tyler et al., 2001) and some others found a complex cortical circuit, mainly fronto-parietal (Perani et al., 1999). The only result that appears to be consistent is the lack of noun-specific areas emerging from direct comparisons (but see Fujimaki et al., 1999), possibly reflecting the fact that the neural circuit underlying lexical access to noun representations is the same as that deputed to verb recognition (see Warburton, Wise, Price et al., 1996).

\subsection{Semantic judgement task}

Semantic judgement tasks on printed words require the same peripheral steps as lexical decision tasks (i.e., orthographic/phonological processing of letters/phonemes and lexical identification), but clearly require participants to process the meaning of the stimuli more thoroughly, rendering the emergence of grammatical class effects more likely. However, the lexical decision experiments illustrated in the previous paragraph indicate that even if the experimental task elicits semantic processing, nouns and verbs do not necessarily generate consistent activations across studies.

Longe, Randall, Stamatakis and Tyler (2007) conducted a factorial-design fMRI experiment focused on contrasting morphologically simple and complex stimuli in a semantic judgement task 
(i.e., requiring the participants to indicate whether the stimulus is pleasant or not). The authors did not obtain activation in the direct noun-verb comparisons when bare stems were considered; on the contrary, when inflected stimuli were analysed, the posterior portion of the left mid temporal gyrus turned out to be associated with verbs, while no area emerged in the nouns-minus-verbs contrast (see Table 2).

In a block-design fMRI experiment, Kable, Lease-Spellmeyer and Chatterjee (2002) used two parallel versions of a forced-choice semantic association task (similar to the Pyramids and Palm Tree test; Howard and Patterson, 1992), one with pictures of objects/actions and one with printed nouns/verbs; this experiment also included a visual matching task on scrambled pictures as a baseline condition. The direct comparison between the object and the action conditions revealed that the lateral occipito-temporal region was activated more by verbs than by nouns. Interestingly, this was not the case in the printed word conditions (although a posterior lateral temporal area of activation for verbs was found when a region-of-interest approach was used; see Table 2).

In three studies conducted by Tyler and colleagues (Tyler et al., 2001; Tyler, Stamatakis, Dick, Bright, Fletcher, and Moss, 2003; Tyler, Bright, Fletcher and Stamatakis, 2004) a semantic judgement task on three consecutive stimuli (quite challenging for the working memory) was compared with a letter identity task (also on three consecutive stimuli). Subjects were shown three words in sequence (two lowercase cue words and an uppercase target word) and had to decide whether the target word was semantically related to both cue words. Within this series of papers, the comparison between the 2001 PET and the 2004 fMRI studies is particularly interesting, as they are similar in everything except the stimuli used, with bare stems being adopted in one study and inflected words in the other. As far as the direct comparison between the two grammatical classes is concerned, neither study found any area that was more active for nouns than verbs, but results are inconsistent with respect to the areas that are more active for verbs than with nouns: the right 
inferior temporal gyrus emerged in the 2001 PET study, while the LIFG turned out to be significant in the 2004 fMRI experiment. In the 2003 study, the authors focused on the comparison between animal nouns and tool nouns, and between biological verbs and tool-related verbs; however, the results do not differ very much along these dimensions. As reflected by the fact that the noun and verb activation patterns largely overlap in the simple effect analyses (see Table $2 \mathrm{~b}$ for more details), very few peaks of activation emerged as grammatical-class-specific in the noun-verb direct comparisons (see Table 2a for details).

\section{TABLE 2 ABOUT HERE}

A further study using letter identity decision as the baseline task was conducted by Davis, Meunier and Marslen-Wilson (2004). Using a one-back synonym-monitoring task in which participants were asked to decide whether each stimulus was a synonym of the immediately preceding item, the authors found activation for verbs in direct comparison with nouns and adjectives in the left posterior middle temporal gyrus. No specific area of activation emerged for nouns (see Table 2).

Tyler, Randall and Stamatakis (2008) used a pleasantness judgement task with visual presentation of nouns and verbs, either in isolation or embedded in short phrase (e.g., a smell, $\underline{I}$ cough). During the baseline condition, participants were presented with the same stimuli as in the experimental condition, but were asked to refrain from responding. They were instructed to look at them without giving any kind of response (passive viewing). The results showed an increased verbrelated activation in the left posterior middle temporal gyrus, while no brain region resulted more active for noun processing as opposed to verb-processing (Table 2). 
With identity decision on nonwords as their baseline, Bedny and Thompson-Schill (2006) investigated the noun and verb processing neural substrate in an imageability-matched design. In this study, participants were presented with a target word followed by a pair of words. They were required to indicate which of the pair was most similar in meaning to the target word. Using an event-related fMRI study and a region-of-interest approach, the authors discovered noun-related activation in the LIFG and the left middle frontal gyrus, while the left superior temporal gyrus was associated with verb processing (see Table 2). The same data, analysed using a whole-brain volume approach, showed greater verb-related activation in the left posterior cingulate gyrus and the left posterior-superior temporal gyrus (though using a lower threshold), while nouns activated the left inferior temporal gyrus (again at a lower threshold) more than verbs.

Palti, Shachar, Hendler and Hadar (2007) also made use of a semantic task in their noun-verb fMRI experiment; however, as this study was based on a more complex factorial design that also included a morphological task, its results will be reported and commented in a separate paragraph.

\subsubsection{Summary of the semantic judgement literature}

The results are not very clear as far as verb processing is concerned: while some authors reported activation in the LIFG and the left insula, fairly strong evidence suggests verb processing is also based in the posterior part of the temporal lobe. Interestingly, none of the studies report evidence for verb-specific activation in both regions. As emerged in the lexical decision experiments, results are somewhat clearer when noun processing is considered. The majority of the studies did not report activation in noun-minus-verbs direct comparisons; the only exception is Bedny and Thompson-Schill (2006), who described noun-related activation in the LIFG and in the left inferior temporal gyrus. 


\subsection{Picture naming tasks}

Most functional dissociations between nouns and verbs in brain-damaged patients emerged in picture naming experiments; therefore, this task is very likely to involve cognitive levels where nouns and verbs are functionally segregated, and thus should be ideal for eliciting consistent grammatical class effects in fMRI. However, picture naming encompasses a visual analysis of the stimulus, object identification, lexical selection, phonological selection and sequencing, and articulation (even if responses are generated sub-vocally in most fMRI studies and thus articulation is not required). Such a broad focus plays against consistency in the results, because different studies might highlight different areas responsible for different cognitive levels due to differences in the baseline or in the stimuli characteristics.

\section{TABLE 3 ABOUT HERE}

In Tranel, Martin, Damasio, Grabowski and Hichwa's PET study (2005), participants were invited to silently name pictures of tools and actions; this experimental condition was compared to an orientation judgement task on unfamiliar faces. The direct comparison analyses revealed that verbs determined more activation than nouns in the left frontal operculum, the left superior temporal sulcus and the left middle temporal gyrus (see Table 3). The choice of a completely non-linguistic task as a baseline makes it very difficult to understand which cognitive processes underlie these brain areas; these results are thus difficult to compare with other data obtained in picture naming experiments.

The same consideration applies to Damasio, Grabowski, Tranel, Ponto, Hichwa, and Damasio (2001). In a picture-naming PET experiment these authors compared lexical retrieval of verbs and 
Nouns and verbs in the brain nouns with an orientation judgement on unfamiliar faces. In the direct comparison analyses, they found bilateral verb-specific activation in the middle temporal gyrus (Table 3). As for Tranel, Martin et al.'s study (2005), the choice of a completely non-linguistic baseline makes this study difficult to interpret in cognitive terms: in fact, the verb-specific activation found in the middle temporal gyrus could reflect lexical retrieval, as well as semantic or phonological processing.

Baseline tasks were not even included in the factorial experimental design employed by Saccuman, Cappa, Bates et al. (2006), and Siri, Tettamanti, Cappa et al. (2008). In the former study, no brain areas passed the FDR-corrected .05 threshold in the verbs-minus-nouns comparison; when a more lenient threshold was adopted, the left inferior parietal lobule, the right fusiform gyrus and the left cerebellum appeared to be associated with verbs. Nouns activated the right cuneus, the posterior cingulate cortex and the right caudate nucleus more than verbs (see Table 3). Siri et al. (2008) employed the same pictures to elicit either action verbs or action nouns in separate experimental blocks; the noun- and verb-related patterns of activation were found to be quite similar in this study (see Table 3a for details).

A similar experimental paradigm was also used by Liljeström, Tarkiainen, Parviainen et al. (2008). In this study the authors employed a picture naming task with action and object images where the action images included the use of an object. The participants were instructed to name the object represented in isolation (Obj condition), or the object represented in the action image (ActObj condition), or the action itself (Act condition). The direct comparison between the ObjAct and the Act condition showed greater activation in the left inferior parietal lobule, in the left precuneus, in the right middle frontal gyrus, in the right superior parietal lobule, and in the right inferior parietal lobule. The reverse contrast (Act-minus-ObjAct) did not show any significant result. On the contrary, when comparing the Act condition with the Obj condition, greater verb-related activation was found in a number of areas located bilaterally in the frontal, temporal, 
and parietal lobes (see Table 3a for details).

Berlingeri and colleagues (2008) used a picture naming task in their factorial-design experiment and reported bilateral verb-specific activation in a wide pattern of areas including frontal, temporal, and parietal regions. None of the brain areas were activated more by nouns than by verbs.

The results of picture-naming neuroimaging experiments are even less clear than those of the PET and fMRI studies using lexical decision and semantic tasks. Verb processing has in fact been reported to be associated with brain areas as diverse as the left frontal operculum, the middle temporal gyrus, the fusiform gyrus, the intra-parietal sulcus, and the cerebellum. The activation peaks which survived in nouns-minus-verbs direct comparisons were located either in the LIFG (frequently reported to be associated with verbs in imaging studies using other tasks; e.g., Perani et al., 1999) or in the right cuneus and posterior cingulate cortex.

Magnetoencefalography (MEG) overcomes the temporal resolution limitations typical of fMRI studies, so that the timing of the neural activity across brain regions can be explored as the stimuli elaboration unfolds. This methodology therefore permits a clearer perception of when noun processing diverges from verb processing, although with a less accurate spatial resolution than fMRI. Some recent data - obtained with Intra-cranial electrophysiology, or ICE, a new technique that, like MEG, allows a millisecond accuracy - have indeed shown that the neural processing of different types of stimuli (or of different aspects of stimuli) might differ more in terms of timing than in terms of their spatial location (e.g., Sahin, Pinker, Cash, Schomer, and Halgren, 2009). It is thus important to integrate results obtained with techniques offering good spatial resolutions - fMRI - with those obtained with techniques offering good temporal resolutions - MEG.

Sörös, Cornelissen, Laine, and Salmelin (2003) used MEG to characterize the brain activation 
pattern associated with noun and verb lexical processing. A picture naming task elicited similar spatio-temporal activation patterns underlying noun and verb retrieval; brain activity started in the occipital areas bilaterally and spread to the posterior temporo-parietal cortex, progressively involving the more anterior regions; in the final steps, activation was reported in the left frontal cortex.

In a recent MEG study Liljeström, Hultén, Parkkonen, and Salmelin (2009) used the experimental paradigm and materials of their previous fMRI study (Liljeström, Tarkiainen, Parviainen et al., 2008) to evaluate the timing and source of activation associated with noun or verb processing. The results indicate stronger early noun-related responses $(100-200 \mathrm{~ms})$ in the posterior channels; however, as Liljeström and colleagues emphasise, the effect of grammatical class disappeared outside this time window, and no other verb/noun effect was found elsewhere.

\subsubsection{Summary of the picture naming literature}

Taken together, the results from picture-naming imaging studies suggest that noun and verb processing is sub-served by the same neural network. However, an overlap between the neural networks underlying noun and verb processing in picture naming might depend, at least in part, on the fact that action pictures unavoidably include the representation of objects and agents involved in the action (e.g., the pictorial representation of the verb "to cut" requires the image of an agent and an instrument, but intransitive actions like "to run" must also include the agent performing the action); to date there is no evidence against the possibility that objects and agents are implicitly processed, thus activating the neural circuits associated with object naming.

\subsection{Morphological tasks}

Morphological tasks have been widely adopted in neuroimaging experiments on noun and verb processing, particularly after the case of the aphasic patient who was able to produce the plural 
forms of nouns, but not to inflect verbs to the third person singular, notwithstanding the fact that these morphological processes are phonologically identical (Shapiro, Shelton, \& Caramazza, 2000). When contrasted with an appropriate baseline, these tasks can isolate morphological processing from other cognitive levels of analysis; fairly consistent results can thus be expected across studies if morphological processing of nouns and verbs recruit different brain areas.

In a PET study, Shapiro, Mottaghy, Schiller et al. (2005) asked German-speaking subjects to inflect nouns or verbs according to a symbolic cue presented immediately before each trial $(*$ prompted the participants to produce the singular form in noun trials and the first-person-singular form in verb trials, while $\stackrel{* *}{*}$ required the subjects to produce the plural form in noun trials and the first-person-plural form in verb trials). Pseudo-word passive viewing and reading constituted the control conditions. In the direct nouns-minus-verbs contrast (masked with the baseline), nouns yielded significant activation in the middle part of the superior temporal gyrus, of the middle portions of the left fusiform gyrus and of the right insula and cerebellum; on the contrary, verbs activated particularly the anterior portion of the left superior frontal gyrus, the including Broca's area and the right cerebellum (see Table 4).

In a later event-related fMRI study conducted in English, Shapiro, Moo and Caramazza (2006) asked the subjects to perform the same inflectional task through completing a phrase that forced the production of a singular/plural target; participants were presented with a stimulus phrase (e.g., one idea) followed by a cue (e.g., many...) that they had to complete. In some trials subjects had to change the morphological form of the stimulus (they were presented with one idea and had to produce many ideas), while in others they had simply to reproduce the original stimulus (they were presented with one idea and had to produce one idea). As in their previous study, in the direct contrast between nouns and verbs the middle/anterior portion of the left fusiform gyrus was more activated by nouns, irrespective of the morphological status of the target word (citation vs. inflected 
form). By contrast, the left prefrontal cortex, the left superior parietal lobule and the left superior temporal cortex were more activated by verbs than by nouns, the latter area also being sensitive to concreteness, morphological regularity and morphological status (citation vs. inflected form).

As emerged from the comparison between the two experiments described above, results only partially overlap even in very similar tasks. The middle portion of the left fusiform gyrus consistently correlates with noun inflection, but the activation in the superior temporal gyrus, the right insula and the right cerebellum were not replicated. Analogously, while the left inferior frontal cortex is associated with verbs in both studies, parietal and temporal areas emerged as associated with verb inflection in the second only.

\section{TABLE 4 ABOUT HERE}

Sahin, Pinker and Halgren (2006) asked participants to complete a small sentence (e.g., Yesterday they... or Those are the...) with a correctly inflected regular or irregular verb/noun; a fixation condition was used as a baseline. The simple contrasts against the baseline showed very similar patterns of activation for verbs and nouns (see Table $4 \mathrm{~b}$ for more details); the only difference was a stronger activation of BA 44/45/47 and the selective activation of the intraparietal sulcus for nouns, as revealed by the direct comparison analyses (Table 4a). This study does not support the findings of Shapiro et al. in either 2005 or 2006, i.e., the association between verb inflection and prefrontal activation. On the contrary, premotor/prefrontal perisylvian regions are significantly more activated by nouns; this is also the case for the intraparietal sulcus, contrary to what is suggested by other results which highlight a role for parietal areas in verb processing (see Berlingeri et al., 2008; Marangolo, Piras, Galati, and Burani, 2006; Shapiro et al., 2006). 
Recently, Burton, Krebs-Noble, Gullapalli and Berndt (2009) investigated the neural network underlying noun and verb processing in a fMRI study. Participants were instructed to express a morphological judgement in a simple sentence context; in particular they were presented with verbs and nouns preceded by either "the" or "to" and were asked to judge whether the sentence was grammatically correct. The results showed noun-specific activation in the left inferior frontal gyrus, while no area was specifically activated by verbs.

Finally, Berlingeri et al. (2008) and Palti et al. (2007) included a morphological task in their factorial-design experiments. In the direct comparison analyses, the former authors reported verb-specific activation in a fronto-parietal bilateral circuit (not including the LIFG or the left insula; see Table 5a) and noun-specific bilateral activation in the LIFG, the left inferior parietal lobule, the left precuneus and the superior and middle occipital gyrus. Palti and colleagues, on the other hand, reported verb-specific activation in the left premotor area which may be in line with the results described by Shapiro and colleagues $(2005 ; 2006)$.

\subsubsection{Summary of the morphological task literature}

Altogether, as was the case for the studies using lexical decision, semantic judgement and picture naming tasks, the results reported above are far from constituting a clear picture: no single brain area emerges as consistently associated with either noun or verb processing in any of the imaging studies using morphological tasks.

\subsection{Fluency tasks}

From a cognitive point of view, fluency tasks seem to encompass the whole word generation process, from search and selection in the lexical-semantic space to phonological encoding and articulation. Due to their broad focus, these tasks are very sensitive in the clinical evaluation of aphasic patients, but when they are used in neuroimaging studies they pose clear limitations on the 
cognitive interpretation of the results; unless the baseline has been very carefully designed, it is hard to know whether an activated area reflects semantic, lexical, phonological, or articulatory processes.

Warburton et al. (1996) conducted a PET study in which subjects were asked to produce as many nouns or verbs as possible, related to a spoken noun used as a cue (Experiment 3); as a control condition, subjects were asked to keep their eyes closed and to "empty their mind". Warburton et al.'s study showed the same activation pattern for verb and noun processing: this pattern spreads over the whole brain with the exclusion of the occipital lobe (see Table $5 \mathrm{~b}$ for more details). When nouns and verbs were directly compared, verb generation produced greater activation in the inferior frontal gyrus, the SMA, the temporal sulcus, the temporo-parietal junction and the inferior parietal lobe, while noun generation activated the right superior frontal sulcus and the left anterior cingulate gyrus. It is virtually impossible to know which cognitive levels are reflected in these activations; therefore, these results contribute little to our understanding of the neural implementation of noun and verb processing. However, the study is theoretically relevant both because it was the first neuroimaging experiment manipulating grammatical class as an independent factor and because it was the first to report that verbs-minus-nouns contrasts generate very wide networks of activation, while nouns-minus-verbs comparisons reveal few brain areas, if any.

TABLE 5 ABOUT HERE

\subsection{Task-by-grammatical-class factorial studies}

As illustrated above, noun and verb activations obtained in studies using different tasks do not converge on the same brain areas. This is also true for tasks tapping similar cognitive levels of 
analysis; this may indicate that brain activations often reflect task-specific effects rather than grammatical class differences. In this respect, an interesting approach has been introduced recently regarding the experimental and baseline tasks used when investigating noun and verb processing. Palti et al. (2007) and Berlingeri et al. (2008) employed factorial experiments in which two different tasks were used, making it possible to address task-dependent as well as task-independent grammatical-class effects. These experimental designs allow a better assessment of whether patterns of brain activation are associated to genuine grammatical class effects rather than to task demand, particularly if the tasks employed share only one cognitive process: brain areas that consistently emerge as associated to a grammatical class in both tasks reflect the processing at that cognitive level and are unlikely to reflect task-specific processing, thus generating results that should be more easy to replicate (for an early suggestion of the advantage of factorial designs in fMRI see Friston, Price, Fletcher, Moon, Frackowiak, \& Dolan, 1996).

Palti and colleagues used a morphological and a semantic task, in which participants were asked to judge whether an auditorily presented noun/verb was inflected in the plural form or was related to a given semantic category. The authors found greater activation for verbs than for nouns across tasks in the LIFG, in the premotor area and in the left superior temporal sulcus, while none of the brain areas were activated more by nouns than by verbs. In a simple effect analysis, the authors also found that the $\mathrm{V}>\mathrm{N}$ effect emerged in the LIFG in the semantic task only, in the premotor area in the morphological task only, and in the left superior temporal sulcus in both tasks. These latter results are very relevant as they show how the experimental task determines the emergence of different grammatical-class-specific areas even when identical stimuli are employed.

Berlingeri et al. (2008) made an explicit use of the potential of factorial designs by using two experimental tasks that share only one specific cognitive process (namely, lexical processing). To this aim, they asked their participants to carry out a picture naming and a grammatical class 
switching task; in this latter, participants were invited to produce the noun/verb corresponding to a verb/noun cue (e.g., applauso, applause, from applaudire, to applaud, or vice versa). This task requires lexical processing in Italian as the morpheme used to produce a deverbal noun is idiosyncratic and cannot be derived by applying a morphological rule, i.e., there is no cue in the verb that safely indicates which deverbal morpheme must be attached to generate a noun (e.g.,

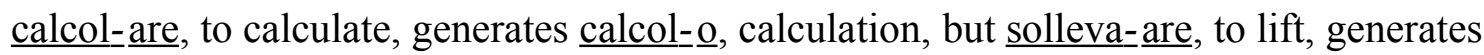
$\underline{\text { solleva-amento, }}$, lifting ${ }_{\mathrm{N}}$ ). In this experiment, verbs were consistently associated with bilateral activation in the precentral and postcentral gyri, the paracentral lobule, the superior parietal lobule and the precuneus, and with activation in the SMA and the inferior parietal lobule in the right hemisphere. No brain area showed greater activation for nouns than for verbs consistently across tasks. Thanks to the factorial design employed, Berlingeri et al. (2008) were also able to identify brain areas where grammatical class interacted with the experimental task; in particular, the left inferior frontal gyrus was found to be predominantly activated by verbs in picture naming, but by nouns in the grammatical-class switching task described above. On the basis of this finding, the authors suggested that the level of activation in the LIFG may reflect the overall cognitive demand imposed by a given task, rather than a firm association with a given grammatical class (see also Bedny, Hulbert, \& Thompson-Schill, 2006; Fiez \& Petersen, 1998; Sabsevitz, Medler, Seidenberg, \& Binder, 2005)

\section{Noun and verb processing in the brain as assessed through TMS}

Only TMS studies investigating the neural basis of nouns and verbs processing in young healthy adults are included in this section.

Studies using repetitive transcranial magnetic stimulation (rTMS) also revealed a relevant impact of the task used to investigate noun and verb processing in the brain. Shapiro, 
Pascual-Leone, Mottaghy, Gangitano and Caramazza (2001) found that prefrontal stimulation (300 $\mathrm{ms}, 1 \mathrm{~Hz}$ ) caused increased response latencies for verbs but not for nouns; on the other hand, Cappa, Sandrini, Rossini, Sosta and Miniussi (2002) obtained the opposite effect (verb-specific facilitation relative to baseline) in a picture naming task after stimulating the same region $(500 \mathrm{~ms}, 20 \mathrm{~Hz})$. These latter findings are particularly striking considering that a stimulation frequency of $20 \mathrm{~Hz}$ is commonly held to cause inhibition in the cerebral cortex: if the dorsolateral prefrontal cortex is directly responsible for verb processing - as suggested by Shapiro et al. (2001) - we would have expected to observe selective inhibition of verb production in Cappa et al.'s study (2002), which was not the case. The diverging results reported by Shapiro et al. (2001) and by Cappa et al. (2002) could be explained by the fact that in the former study subjects were asked to carry out a morphological task, while in the latter they had to name pictures; however, this would indicate that frontal regions are crucial for inflecting verbs, but not for retrieving them, in conflict with some fMRI and PET evidence (e.g., Saccuman et al., 2006; Sahin et al., 2006). Oliveri, Finocchiaro, Shapiro, Gangitano, Caramazza, and Pascual Leone (2004) conducted a further rTMS study, in which the left primary motor cortex was found to play a critical role in the retrieval of action words irrespective of their grammatical class (i.e. both nouns and verbs); once again the task was to inflect a visually presented word following a cue in the form of a symbol, indicating whether the verb/noun had to be produced in the singular or in the plural form.

On the basis of these results, Lo Gerfo, Olivieri, Torriero, Salerno, Koch, and Caltagirone (2008) explored the role of the prefrontal cortex and of the primary motor cortex in both verb and action processing. They too used a morphological task, similar to that used by Shapiro and colleagues (2001) and by Olivieri et al. (2004). Results showed that when rTMS was applied to the left prefrontal cortex, there was a selective delay in action verb retrieval. On the contrary, an rTMS impulse applied to the left motor cortex caused a significant delay in processing action words, 
irrespective of grammatical class. Although these results seem to better clarify the role of the frontal area in verb/action processing, the choice of a pure morphological task rather than another type of task does not in itself contribute to deciding whether the role of the prefrontal cortex is specific for verb inflection or more generally associated to verb lexical-semantic processing.

In order to address this issue, Cappelletti, Fregni, Shapiro, Pascual-Leone and Caramazza (2008) recently explored the role played by distinct parts of the prefrontal cortex in noun and verb production within a phrasal context. They obtained a significant increase in response latencies for verb production when stimulating the left anterior midfrontal gyrus. No significant verb-specific interference effect was found after the stimulation of the posterior middle frontal gyrus and the Broca's area and, in addition, none of these regions was preferentially involved in the production of either regular or irregular inflection.

\section{Cortical stimulation in pre-surgical patients}

Corina, Gibson, Martin, Poliakov, Brinkley, and Ojemann (2005) investigated the neural representation of verbs and nouns in 13 neurosurgical subjects undergoing cortical mapping while awake. In this study nouns yielded a quite coherent frame: inability to name object pictures was consistently caused by cortical stimulation of the left anterior superior and of the left middle temporal gyrus. On the contrary, the areas causing inability to name verbs varied remarkably across participants, including the left middle superior temporal gyrus, the left supramarginal gyrus and the left posterior middle temporal gyrus. Unfortunately, due to technical/clinical constraints it was not possible to stimulate any frontal areas; however, the study clearly highlights an important role of the temporal regions in retrieving verbs. Ojemann, Ojemann and Lettich (2002) had conducted a similar experiment some years before, but with two important differences: frontal regions were also stimulated and a verb generation task instead of a picture naming task was used to elicit verbs. This 
Nouns and verbs in the brain

study confirmed that verb-specific areas may vary notably across subjects: in 3 out of the 13 participants tested, both frontal and temporal stimulation caused verb-specific deficits; in 2 participants, a verb deficit appeared after frontal stimulation, whereas it emerged after temporal stimulation in another 8 participants. Altogether, temporal verb-related areas seemed to be more specific than frontal verb-related areas: in fact, among the 13 frontal sites in which stimulation hampered verb generation, 7 also caused an object-naming deficit. On the contrary, however, 12 out of 20 temporal verb-specific sites were located at least $1 \mathrm{~cm}$ away from any object-naming related site (mostly located in the posterior part of the medial and upper temporal gyrus and in the supramarginal gyrus). Altogether, direct cortical stimulation studies emphasize the role of the posterior temporal lobe in retrieving verbs, as well as great across-subject variability regarding the exact localization of the neural sites, which, when stimulated, hindered either noun or verb lexical retrieval.

\section{Discussion}

There is clearly a great deal of inconsistency in the evidence described in this paper. It might have been expected that the different experimental techniques adopted (e.g., anatomo-clinical correlations, fMRI, MEG) and various behavioural tasks used to investigate the anatomical underpinnings of noun and verb processing would account for the discrepancies, but contrasting findings were reported even in studies using the same methodology and, in several cases, also the same experimental tasks (e.g., Perani et al., 1999 and Tyler et al., 2001; Siri et al., 2008 and Saccuman et al., 2006; Shapiro et al., 2001 and Cappa et al., 2002). The presence of inconsistent results within task and methodology makes it even less appropriate to compare results across tasks and methodologies.

The discrepancies do not seem to be due to technical details (e.g., statistical threshold, sample 

size) - which have been shown to influence the outcome of imaging studies (e.g., Friston, 2005) or to noise signals - which unavoidably affect the dependent variable in neuroimaging experiments. If this were the case, we would expect some random noise over a set of rather consistent results; but no such set of results emerged in our review. Indeed, the results are very inconsistent overall. This may be due simply to methodological aspects and sources of noise intrinsic to the methodology; however, this would basically imply that neuroimaging data are so poorly replicable to be of little scientific utility overall.

The fronto-temporal dichotomy hypothesis $(\mathrm{FTDH})$ put forward in several anatomo-correlative and neuroimaging studies, and supported by Cappa and Perani in a previous review (2003), is far from being even partially confirmed. According to the FTDH, (left) frontal areas underlie verb processing, whereas the (left) temporal region is the cerebral counterpart of noun processing. However, of 28 neuroimaging studies, only 14 have reported a frontal area specifically activated by verbs in either simple contrasts or direct comparisons, while 14 have failed to do so and 6 of these 14 studies have even found noun-specific frontal area activation (Martin, Wiggs, Ungerleider, \& Haxby, 1996; Chao \& Martin, 2000; Tyler et al., 2003; Sahin et al., 2006; Bedny \& Thompson-Schill, 2006; Siri et al., 2008). Noun-related activation in the frontal areas was generally obtained with tool nouns (e.g., Martin et al., 1996; Tyler et al., 2003), but this category-specificity was not confirmed in other similar studies; for example, Tyler et al. (2003) and Sahin et al. (2006) found frontal activation associated with nouns that did not refer to manipulable objects.

Furthermore, the FTDH obviously predicts the emergence of frontal activation associated with verbs and temporal activation associated with nouns in direct comparison analyses; however, of the 15 imaging studies reporting verb-noun direct contrasts, only 5 found verb-related activation in frontal areas (Perani et al., 1999; Shapiro et al., 2005; Shapiro et al., 2006; Tyler et al., 2003; Tyler et al., 2004) and only 2 showed noun-related activation in temporal areas (Shapiro et al., 2005; 
Shapiro et al., 2006). A word of caution should be spent here on the fact that, in this line of reasoning, positive and negative evidence for the FTDH are given the same weight, whereas the common process of statistical inference adopted in neuroimaging studies (and in the whole field of psychology, in fact) is somewhat biased towards positive findings, while negative results may remain not fully assessed. Figure 1 illustrates a more detailed analyses of how many studies reported noun or verb-specific activations in either simple effects or direct comparisons; even at a finer spatial resolution (i.e., considering separately different portions of the inferior frontal gyri and of the temporal lobes), no frontal area is specifically associated with verbs, nor any temporal area is specifically associated with nouns. It is clear that the FTDH does not survive confrontation with the evidence available to date.

FIGURE 1 ABOUT HERE

The problem seems to be that no alternative coherent frame has emerged from this review. Alternatively to the FTDH, the neurolinguistic evidence discussed at the beginning of the paper suggested that verb processing was most likely carried out by a wide neural circuit involving not only frontal, but also parietal areas (e.g., Silveri et al., 2003) and sub-cortical structures bridging the anterior-posterior communication (e.g., Aggujaro et al., 2006; see also Mätzig et al., 2009). However, this hypothesis would predict consistent joint fronto-parietal activation in neuroimaging studies, which is clearly not the case. This might be explained by the existence of various sub-circuits within the wider network, each of which might be specialized in specific linguistic processing components (e.g., lexical vs. semantic vs. morphological). If this were the case, there would be no reason to expect fronto-temporal activation in all neuroimaging studies; we should 
instead be able to identify consistent associations between specific tasks (i.e., specific cognitive processes) and smaller networks of frontal and parietal areas. However, imaging data turned out to be inconsistent even among studies using the same task; once again, this lack of consistency within tasks makes comparing results across tasks of little use.

The most recent fMRI studies adopting a factorial approach (Berlingeri et al., 2008; Palti et al., 2007) have certainly taken a step forward by searching for brain areas that show grammatical class effects consistently across different tasks tapping on similar cognitive processes. These studies have provided convincing evidence that retro-rolandic areas (like the left superior temporal sulcus and the posterior parietal region) play an important role in the lexical-semantic processing of verbs; the question however remains as to why these areas have not been found more consistently in previous studies. One possible reason is that previous studies were not so specific in their focus on lexical processing as Berlingeri et al. (2008) and thus found activations that also reflected other cognitive levels; moreover, task-specific activations might have blurred the results in single-task paradigms, even when lexical processing was well targeted through careful design of the experimental and the baseline tasks. In addition to these design-related explanations, more general factors such as differences in the lexical-semantic characteristics (e.g., word frequency, actionality) of the verbs used in the different studies might have contributed to the underestimation of the role of the parietal and posterior temporal areas in verb processing.

Such an inhomogeneous pattern of results might depend on the fact that nouns normally refer to objects while verbs mostly refer to actions, thus making the lexical-syntactic dichotomy hard to distinguish from the conceptual one. Indeed, some authors have discussed their results in terms of object-vs.-action effects rather than in terms of grammatical class (e.g., Kable et al., 2002). Moreover, semantic category effects have been demonstrated within grammatical class in several studies. This hypothesis is weakened by the argument that replicability of results should be 
independent from their theoretical interpretation: for example, when comparing the brain activations elicited by "cake" and "writing", the same results should emerge in two identical experiments irrespective of whether the difference is due to grammatical class, or to cake being an object and eating an action.

Another important lexical-semantic distinction contrasts movement verbs vs. non-movement verbs. According to recent findings (e.g., Bak, Yankopoulou, Nestor, et al., 2006), the semantic representations in the former category are heavily based on motor information, thus relying on completely different neural circuits including the posterior parietal (Berlingeri et al., 2008) and the primary motor cortex (Hauk, Johnsrude, \& Pulvermuller, 2004). Although some data are in line with this suggestion (e.g., Kemmerer, Gonzalez Castillo, Talavage, Patterson, \& Wiley, 2008), the results of two studies that investigated tool-related motor verbs in the context of the same experimental task (i.e., picture naming) are very informative in this respect; while Saccuman et al. (2006) report that verbs activate the left inferior parietal lobule, the right fusiform gyrus, and the left cerebellum more than nouns, Damasio et al. (2001) describe significant verb-related activations in the mid temporal gyrus bilaterally. Hence the neural circuits described in the two studies do not overlap even though the same class of verbs was investigated. Some recent results also suggest the existence of verb-specific activation in the posterior-lateral-temporal cortex, independently of whether verbs refer to motion or to mental states (Bedny, Caramazza, Grossman, Pascual-Leone, \& Saxe, 2008; see also Aggujaro et al., 2006, for similar findings in neuropsychology). Of course, these considerations do not deny that different types of verbs in different studies might be the cause of these discrepancies; however, this factor does not seem to be the primary cause of such vast inconsistency in the data.

If not explained by lexical-semantic co-varying factors, this lack of consistency across studies investigating the anatomical underpinnings of noun and verb processing might suggest, more 
simply, that the neural circuits ultimately distinguishing nouns and verbs on anatomical grounds are not spatially segregated, leading to noun- or verb-specific brain areas that can be reliably detected by neuroimaging, TMS, or anatomo-correlative studies. Rather, these neural circuits would be located spatially close to each other in the brain areas that are most frequently reported in the literature, namely, the LIFG, the left insula, the middle and inferior lateral temporal regions and the left inferior and superior parietal gyri, which most likely also host neural circuits that are responsible for both noun and verb processing. Moreover, these areas might also underlie cognitive processes that are not specifically linguistic in nature, but which are called upon by most tasks used to elicit noun or verb production and comprehension (e.g., task monitoring, attentional processes, cognitive resource assignment; see Bedny and Thompson-Schill, 2006; Berlingeri et al., 2008; Crescentini, Shallice, \& Macaluso, 2009).

Of course, this hypothesis does not imply that the neural circuits underlying noun and verb processing overlap completely. Certainly, there are neural aggregates that are not called upon by both grammatical classes; otherwise, neuropsychological dissociations in brain-damaged patients would never be possible. What we are suggesting here is that grammatical-class specific circuits may not cluster into separate brain areas; rather, they may be dispersed in different parts of the brain and be interleaved with neural structures that are shared by nouns and verbs and that also sub-serve other cognitive functions. This specification should also make clearer that this proposal is indeed compatible with those neuroimaging experiments that do find noun-verb effects. These effects, however, may not be easily replicated because grammatical-class-specific structures do not reach the critical dimension to become consistently visible at the spatial resolution normally allowed by current neuroimaing experiments.

This suggestion would also be in line with evidence from the fMRI and MEG studies carried out by Liljestrom and colleagues $(2008,2009)$. These studies suggest that the neural networks 
underlying noun and verb processing overlap for the most part; in addition, the activation dynamics (i.e., the temporal distribution of the neural activations) are also very similar for nouns and verbs.

What this hypothesis implies is that there is no one-to-one mapping between anatomical and cognitive units at the level of analysis that is currently adopted by most anatomo-functional studies on the noun-verb dichotomy. On the one hand, the anatomical regions (gyri or Brodmann areas) usually highlighted in imaging studies do not really correspond to single functional units, but often correspond to several independent functional units (for example, the LIFG has been reported to be responsible for the morphological processing of verbs, the semantic processing of verbs, the semantic processing of nouns, the lexical retrieval of nouns, and even more general, non-linguistic abilities like the recollection of autobiographical memories, e.g., Meulenbroek, Rijpkema, Kessels, Rikkert \& Fernandez, 2010). On the other hand, any single cognitive process can be carried out in circuits that are spread over several brain areas. Thus, the inconsistency across studies may arise from the fact that our technical, statistical and theoretical tools do not allow to capture univocal correlations between the anatomical and the functional side. To illustrate with an example, suppose that the LIFG hosts part of the neural circuit responsible for the lexical retrieval of nouns and part of the neural circuit responsible for the lexical retrieval of verbs, and that these circuits are modulated by the cognitive demand imposed by the task. In such a situation, it is easy to see that activation in the LIFG may emerge in association with nouns, or with verbs, or with both, or with neither grammatical class, depending on the specific experimental settings of the study (e.g., task, stimuli, statistical analysis).

Sahin et al. (2009) have recently published a study that is illuminating in this respect, even if it only marginally addresses the issue of grammatical class. Using Intra-cranial Electrophysiology (ICE, a technique that has the advantage of being quite accurate both in timing and in spatial resolution), they found evidence for lexical, syntactic, and phonological processing in Broca's area 
(BA 45) at different time windows after the presentation of the stimulus ( $200 \mathrm{~ms}, \sim 320 \mathrm{~ms}$, and $\sim$ $450 \mathrm{~ms}$, respectively); these authors also report that the neurofunctional signal reflecting these cognitive steps is similar for nouns and verbs. There are several reasons why this study helps to clarify this hypothesis. Firstly, the results show that a unique brain area (Broca's area) sub-serves different levels of processing (lexical, syntactic, and phonological), i.e., anatomo-functional mapping is not one-to-one, but one-to-many. Secondly, the different time windows identified by Sahin et al. are well below the temporal resolution of fMRI; it would therefore appear that this technique would never be able to disentangle lexical, syntactic, and phonological processing in Broca's area, unless the design of the experimental and baseline tasks were to isolate one of these levels of processing. Thirdly, even at such a fine temporal and spatial ${ }^{3}$ resolution, circuits for noun and verb processing were not distinguishable at lexical, grammatical or phonological level; this would imply that either processing of nouns and verbs rely on the same circuitry in this area, or that brain cells deputed to noun and verb processing are indeed separate but intermingled in this same area.

On the basis of these considerations, it seems that a clear understanding of the cerebral circuits responsible for noun and verb processing requires neuroimaging studies to:

(i) Conduct a fine-grained cognitive analysis of the tasks used;

(ii) Design experimental and baseline tasks to specifically isolate one single cognitive process;

(iii) Make use of factorial designs that allow better control over task-specific effects and allow to identify areas that are specific for grammatical class across tasks (through conjunction analysis);

${ }^{3}$ It is difficult to determine precisely the spatial resolution of Sahin et al.'s (2009) intracranial recordings; however, it was certainly in the range of 1-2 mm, considering that at least 14 bipolar channels were recorded in the Broca's area of each patient. 
(iv) Make full use of the spatial resolution achieved by imaging techniques, i.e., do not limit their analyses to the Brodmann areas or anatomical gyri, but report and comment their results on the basis of smaller cortical areas;

(v) Search for converging evidence from complementary techniques like MEG and EEG, which offer better temporal resolution than fMRI.

These guidelines could help researchers to address the issue of noun/verb processing in the brain at a level of analysis where the relationship between functional and anatomical units is likely to be clearer, thus facilitating more consistent and replicable results.

As a closing remark, we note that the data reviewed in this paper do not constitute evidence against functional modularity in the human mind, and do not exclude anatomical modularity in other cognitive domains (e.g., object identification, Borowsky, Loher, Kelland et al., 2005), provided that an adequate spatial resolution is considered. 


\section{Acknowledgements}

The present study was conducted for the most part at the University of Milano-Bicocca, although the manuscript was partially prepared while the first author was at the Royal Holloway, University of London, funded by a post-doctoral fellowship granted by the Economic and Social Research Council, United Kingdom; he gratefully acknowledges this contribution. This work has been partly funded by the grant PRIN 20074EKLSX_002 awarded to Claudio Luzzatti by the Italian Ministry of University and Research, and by the grant PRIN 2007JLKBL9_002 awarded to Eraldo Paulesu by the same institution. 


\section{References}

Aggujaro, S., Crepaldi, D., Pistarini, C., Taricco, M., \& Luzzatti, C. (2006). Neuro-anatomical correlates of impaired retrieval of verbs and nouns: Interaction of grammatical class, imageability and actionality. Journal of Neurolinguistics, 19, 175-194.

Bak, T.H., Yancopoulou, D., Nestor, P., Xuereb, H.J., Spillantini, M.G., Pulvermuller, F., \& Hodges, J.R. (2006). Clinical, imaging and pathological correlates of a hereditary deficit in verb and action processing. Brain, 129, 321-332.

Bastiaanse, R., \& Jonkers, R. (1998). Verb retrieval in action naming and spontaneous speech in agrammatic and anomic aphasia. Aphasiology, 12, 951-969.

Bedny, M., Caramazza, A., Grossman, E., Pascual-Leone, A., \& Saxe, R. (2008). Concepts are more than percepts: the case of action verbs. The Journal of Neuroscience, 28, 11347-11353.

Bedny, M., Hulbert, J. C., \& Thompson-Schill, S. L. (2007). Understanding words in context: the role of Broca's area in word comprehension. Brain Research, 1146, 101-114.

Bedny, M., \& Thompson-Schill, S.L. (2006). Neuroanatomically separable effects of imageability and grammatical class during single-word comprehension. Brain and Language, 98, 127-139.

Berlingeri, M., Crepaldi, D., Roberti, R., Scialfa, G., Luzzatti, C., \& Paulesu, E. (2008). Nouns and verbs in the brain: Grammatical class and task specific effects as revealed by fMRI. Neuropsychology, 25, 528-558.

Berndt, R.S., Mitchum, C.C., Haendiges, A.N., \& Sandson, J. (1997a). Verb retrieval in aphasia. 1. Characterizing single word impairments. Brain and Language, 56, 68-106.

Berndt, R.S., Mitchum, C.C., Haendiges, A.N., \& Sandson, J. (1997b). Verb retrieval in aphasia. 2. Relationship to sentence processing. Brain and Language, 56, 107-137.

Bird, H., Howard, D., \& Franklin, S. (2000). Why is a verb like an inanimate object? Grammatical category and semantic category deficits. Brain and Language, 72, 246-309. 
Borowsky, R., Loehr, J., Kelland Friesen, C., Kraushaar, G., Kingstone, A., \& Sarty, G. (2005). Modularity and intersection of "what", "where" and "how" processing of visual stimuli: A new method of method of fMRI localization. Brain Topography, 18, 67-75.

Burton, M., Krebs-Noble, D., Gullapalli, R., \& Berndt, R. (2009). Functional neuroimaging of grammatical class: ambiguous and unambiguous nouns and verbs. $\underline{\text { Cognitive }}$ Neuropsychology, 26, 148-171.

Cappa, S.F., \& Perani, D. (2003). The neural correlates of noun and verb processing. Journal of Neurolinguistics, $16,183-189$.

Cappa, S.F., Sandrini, M., Rossini, P.M., Sosta, K., \& Miniussi, C. (2002). The role of the left frontal lobe in action naming: rTMS evidence. Neurology, 59, 720-723.

Cappelletti, M., Fregni, F., Shapiro, K., Pascual-Leone, A. and Caramazza A. (2008). Processing Nouns and Verbs in the Left Frontal Cortex: A Transcranial Magnetic Stimulation Study. Journal of Cognitive Neuroscience, 20, 707-720.

Caramazza, A., \& Hillis, A. (1991). Lexical oragnization of nouns and verbs in the brain. Nature, 349, 788-790.

Chao, L.L., \& Martin, A. (2000). Representation of manipulable man-made objects in the dorsal stream. NeuroImage, 12, 478-484.

Chomsky, N. (1995). The Minimalist Program. Cambridge: MIT Press.

Crepaldi, D., Aggujaro, S., Arduino, L.S., Zonca, G., Ghirardi, G., Indaghi, M., Colombo, M., Chierchia, G., \& Luzzatti, C. (2006). Noun-verb dissociation in aphasia: The role of imageability and functional locus of the lesion. Neuropsychologia, 44, 73-89.

Crepaldi, D., Ingignoli, C., Verga, R., Contardi, A., Semenza, C., \& Luzzatti, C. (in press). On nouns, verbs, and lemmas: Evidence from the spontaneous speech of seven aphasic patients. Aphasiology. 
Crescentini, C., Shallice, T., \& Macaluso, E. (in press). Item retrieval and competition in noun and verb generation: An fMRI study. Journal of Cognitive Neuroscience.

Corina, D.P., Gibson, E.K., Martin, R., Poliakov, A., Brinkley, J., \& Ojemann, G.A. (2005). Dissociation of action and object naming: Evidence from cortical stimulation mapping. Human Brain Mapping, 24, 1-10.

Damasio, H., Grabowski, T.J., Tranel, D., Ponto, L.L.B., Hichwa, R.D., \& Damasio, A.R. (2001). Neural correlates of naming actions and of naming spatial relations. Neuroimage, 13, 1053 1064.

Damasio, A.R., \& Tranel, D. (1993). Nouns and verbs are retrieved with differently distributed neural systems. Proceedings of the National Academy of Science (USA), 90, 4957-4960.

Daniele, A., Giustolisi, L., Silveri, M.C., Colosimo, C., \& Gainotti, G. (1994). Evidence for a possible neuroanatomical basis for lexical processing of nouns and verbs. Neuropsychologia, $32,1325-1341$.

Davis, M.H., Meunier, F., \& Marslen-Wilson, W.D. (2004). Neural responses to morphological, syntactic and semantic properties of single words: An fMRI study. Brain and Language, 89, 439-449.

de Diego Balaguer, R., Rodriguez-Fornells, A., Rotte, M., Bahlmann, J., Heinze, H.-J., \& Münte, T. (2006). Neural circuits sub-serving the retrieval of stems and grammatical features in regular and irregular verbs. Human Brain Mapping, 2, 874-888.

De Renzi, E., \& Di Pellegrino, G. (1995). Sparing of verbs and preserved, but ineffectual reading in a patient with impaired word production. Cortex, 31, 619-636.

Fiez, J. A., \& Petersen, S. E. (1998). Neuroimaging studies of word reading. Proceedings of the National Academy of Science of the United States of America, 95, 914-921.

Foley, W.A. (1998). Symmetrical Voice Systems and Precategoriality in Philippine Languages. 
Brisbane: Workshop on Voice and Grammatical Functions in Austronesian.

Friedmann, N. (2000) Moving verbs in agrammatic production. In Bastiaanse, R., Grodzinsky, J.

(Ed.), Grammatical Disorders in Aphasia: A Neurolinguistic Perspective. London: Whurr.

Frings, M., Dimitrova, A., Schorn, C.F., Elles, H.-G., Hein-Kropp, C., Gizewsky, E.R., Diener, H.C., \& Timmann, D. (2006). Cerebellar involvement in verb generation: An fMRI study. Neuroscience Letters, 409, 19-23.

Friston, K.J. (2005). Models of brain function in neuroimaging. Annual Review of Psychology, 56, $57-87$.

Friston, K. J., Price, C. J., Fletcher, P., Moore, C., Frackowiak, R. S., \& Dolan, R. J. (1996). The trouble with cognitive substraction. Neuroimage, 4, 97-104.

Fujimaki, N., Miyauchi, S., Putz, B., Sasaki, Y., Takino, R., Sakai, K., \& Tamada, T. (1999). Functional magnetic resonance imaging of neural activity related to orthographic, phonological, and lexico-semantic judgments of visually presented characters and words. Human Brain Mapping, 8, 44-59.

Glosser, G., \& Donofrio, N. (2001). Differences between nouns and verbs after anterior temporal lobectomy. Neuropsychology, 15, 39-47.

Grossman, M., Koenig, P., DeVita, C., Glosser, G., Alsop, D., Detre, J., \& Gee, J. (2002). Neural representation of verb meaning: An fMRI study. Human Brain Mapping, 15, 124-134.

Hauk, O., Shtyrov, Y., \& Pulvermuller, F. (2008). The time course of action and action-word comprehension in the human brain as revealed by neurophysiology. Journal of Physiology$\underline{\text { Paris, }}$ 102, 50-58.

Hillis, A., \& Caramazza, A. (1995). Representation of grammatical knowledge in the brain. Journal of Cognitive Neuroscience, 7, 369-407.

Hillis, A.E., Tuffiash, E., Wityk, R.J., \& Barker, P.B. (2002). Regions of neural dysfunction 
associated with impaired naming of actions and objects in acute stroke. Cognitive Neuropsychology, 19, 523-534.

Holmes, J.M., Marshall, J.C., \& Newcombe, F. (1971). Syntactic class as a determinant of word-retrieval in normal and dyslexic subjects. Nature, 234, 418.

Howard, D. \& Patterson, K. (1992). The Pyramids and Palm Trees Test. Bury St Edmunds: Thames Valley Test Company.

Kable, J.W., Lease-Spellmeyer, J., \& Chatterjee, A. (2002). Neural substrate of action event knowledge. Journal of Cognitive Neuroscience, 14, 795-805.

Kemmerer, D., Gonzalez Castillo, J., Talavage, T., Patterson, S., \& Wiley, C. (2008).

Neuroanatomical distribution of five semantic components of verbs: Evidence from fMRI. Brain and Language, 107, 16-43.

Langacker, R.W. (1987). Nouns and verbs. Language, 63, 53-94.

Levelt, W.J.M., Roelofs, A.P.A., \& Meyer, A.S. (1999). A theory of lexical access in speech production. Behavioral and Brain Sciences, 22, 1-37.

Li, P., Jin, Z., \& Tan, L.H. (2004). Neural representation of nouns and verbs in Chinese: an fMRI study. NeuroImage, 21, 1533-1541.

Liljeström, M., Hultén, A., Parkkonen, L., \& Salmelin, R. (2009). Comparing MEG and fMRI views to naming actions and objects. Human Brain Mapping, 30, 1845-1856.

Liljeström, M., Tarkiainen, A., Parviainen, T., Kujala, J., Numminen, J., Hiltunen, J., et al. (2008). Perceiving and naming actions and objects. Neuroimage, 41, 1132-1141.

Lo Gerfo, E., Olivieri, M., Torriero, S., Salerno, S., Koch, G. \& Caltagirone C. (2008). The influence of rTMS over prefrontal and motor areas in a morphological task: Grammatical vs. semantic effects. Neuropsychologia, 46, 764-770.

Longe, O., Randall, B., Stamatakis, E.A., \& Tyler, L.K. (2007). Grammatical categories in the 
brain: The role of morphological structure. Cerebral Cortex, 17, 1812-1820.

Luzzatti, C., Raggi, R., Zonca, G., Pistarini, C., Contardi, A., \& Pinna, G.D. (2002). Verb-noun double dissociation in aphasic lexical impairments: The role of word frequency and imageability. Brain and Language, 81, 432-444.

Marangolo, P., Piras, F., Galati, G., \& Burani, C. (2006). Functional anatomy of derivational morphology. Cortex, 42, 1093-1106.

Martin, A., Wiggs, C. L., Ungerleider, L. G., \& Haxby, J. V. (1996). Neural correlates of category-specific knowledge. Nature, 379, 649-652.

Mätzig, S., Druks, J., Masterson, J., \& Vigliocco, G. (2009). Noun and verb differences in picture naming: past studies and new evidence. Cortex, 45, 738-758.

McCarthy, R., \& Warrington, E.K. (1985). Category specificity in an agrammatic patient: the relative impairment of verb retrieval and comprehension. Neuropsychologia, 23, 709-727.

Meulenbroek, O., Rijpkema, M., Kessels, R.P.C., Rikkert, M.G.M.O., \& Fernandez, G. (2010). Autobiographical memory retrieval in patients with Alzheimer's disease. Neuroimage, 53, $331-340$.

Miceli, G., Silveri, M.C., Villa, G., \& Caramazza, A. (1984). On the basis for the agrammatic's difficulty in producing main verbs. Cortex, 20, 207-240.

Newman, S.D., Twieg, D.B., \& Carpenter, P.A (2001). Baseline conditions and subtractive logic in neuroimaging. Human Brain Mapping, 12, 228-235.

Ojemann, J.G., Ojemann, G.A., \& Lettich, E. (2002). Cortical stimulation mapping of language cortex by using a verb generation task: effects of learning and comparison to mapping based on object naming. Journal of Neurosurgery, 97, 33-38.

Oliveri, M., Finocchiaro, C., Shapiro, K., Gangitano, M., Caramazza, A., \& Pascual Leone, A. (2004). All talk and no action: A transcranial magnetic stimulation study of motor cortex 
activation during action word production. Journal of Cognitive Neuroscience, 16, 374-381.

Palti, D., Shachar, M.B., Hendler, T., \& Hadar, U. (2007). Neural correlates of semantic and morphological processing of Hebrew nouns and verbs. Human Brain Mapping, 28, 303-314.

Paulesu, E., Shallice, T., Danelli, L., Frackowiak, R.S.J., \& Frith, C.D. (submitted). Anatomical modularity of verbal working memory: evidence from a much studied patient.

Perani, D., Cappa, S.F., Schnur, T., Tettamanti, M., Collina, S., Rosa, M.M., \& Fazio, F. (1999). The neural correlates of verb and noun processing. A PET study. Brain, 122, 2337-2344.

Perea, M. \& Rosa, E. (2002). The effects of associative and semantic priming in the lexical decision task. Psychological Research, 66, 180-194.

Rapp, B., \& Caramazza, A. (2002). Selective difficulties with spoken nouns and written verbs: a single case study. Journal of Neurolinguistics, 15, 373-402.

Rastle. K. \& Brysbaert, M. (2006). Masked phonological priming effects in English: Are they real? Do they matter? Cognitive Psychology, 53, 97-145.

Robins, R.H. (1952). Noun and verb in universal grammar. Language, 28, 289-298.

Rowan, A., Liégeois, F., Varga-Khadem, F., Gadian, D., Connelly, A., \& Baldeweg, T. (2004). Cortical lateralization during verb generation: a combined ERP and fMRI study. NeuroImage, $22,665-675$.

Sabsevitz, D. S., Medler, D. A., Seidenberg, M., \& Binder, J. R. (2005). Modulation of the semantic system by word imageability. Neuroimage, 27, 188-200.

Saccuman, M.C., Cappa, S.F., Bates, E.A., Arevalo, A., Della Rosa, P., Danna, M., \& Perani, D. (2006). The impact of semantic reference on word class: An fMRI study of action and object naming. NeuroImage, 32, 1865-1878.

Sahin, N. T., Pinker, S., Cash, S. S., Schomer, D., \& Halgren, E. (2009). Sequential processing of lexical, grammatical, and phonological information within Broca's area. Science, 326, 445-449. 
Sahin, N.T., Pinker, S., \& Halgren, E. (2006). Abstract grammatical processing of nouns and verbs in Broca's area: Evidence from fMRI. Cortex, 42, 540-562.

Shapiro, K., \& Caramazza, A. (2003). Looming a loom: Evidence for independent access to grammatical and phonological properties in verb retrieval. Journal of Neurolinguistics, 16 , 85-111.

Shapiro, K., Moo, L.R., \& Caramazza, A. (2006). Cortical signatures of noun and verb production. Proceedings of the National Academy of Sciences of USA, 103, 1644-1649.

Shapiro, K., Mottaghy, F.M., Schiller, N.O., Poeppel, T.D., Fluss, M.O., Muller, H.W., Caramazza, A., \& Krause, B.J. (2005). Dissociating neural correlate for verbs and nouns. Neuroimage, 24, $1058-1067$.

Shapiro, K., Pascual-Leone, A., Mottaghy, F.M., Gangitano, M., \& Caramazza, A. (2001). Grammatical distinction in the left frontal cortex. Journal of Cognitive Neuroscience, 13, 713720.

Shapiro, K., Shelton, J., \& Caramazza, A. (2000). Grammatical class in lexical production and morhpological processing: Evidence from a case of fluent aphasia. Cognitive Neuropsychology, 17, 665-682.

Silveri, M.C., \& Di Betta, A.M. (1997). Noun-verb dissociations in brain-damaged patients: further evidence. Neurocase, 3, 477-488.

Silveri, M., Perri, R., \& Cappa, A. (2003). Grammatical class effects in brain-damaged patients: Functional locus of noun and verb deficit. Brain and Language, 85, 49-66.

Siri, S., Tettamanti, M., Cappa, S.F., Della Rosa, P., Saccuman, C., Scifo, P., \& Vigliocco, G. (2008). The neural substrate of naming events: Effects of processing demands but not grammatical class. Cerebral Cortex, 18, 171-177.

Sörös, P., Cornelissen, K., Laine, M., \& Salmelin, R. (2003). Naming actions and objects: cortical 
dynamics in healthy adults and in an anomic patient with a dissociation in action/object naming. Neuroimage, 19, 1787-1801.

Thompson, C.K., Bonakdarpour, B., Fix, S.C., Blumenfeld, H.K., Parrish, T.B., Gitelman, D.R., \& Marsel-Mesulam, M. (2007). Neural correlates of verb argument structure processing. Journal of Cognitive Neuroscience, 19, 1753-1767.

Tranel, D., Grabowski, T. J., Lyon, J., \& Damasio, H. (2005). Naming the same entities from visual or from auditory stimulation engages similar regions of left inferotemporal cortices. $\underline{\text { Journal of }}$ Cognitive Neuroscience, $17,1293-305$.

Tranel, D., Manzel, K., Asp, E., \& Kemmerer, D. (2008). Naming dynamic and static actions: Neuropsychological evidence. Journal of Physiology - Paris, 102, 80-94.

Tranel, D., Martin, C., Damasio, H., Grabowski, T. J., \& Hichwa, R. (2005). Effects of noun-verb homonymy on the neural correlates of naming concrete entities and actions. Brain and Language, 92, 288-299.

Tyler, L.K., Bright, P., Fletcher, P., \& Stamatakis, E.A. (2004). Neural processing of nouns and verbs: the role of inflectional morphology. Neuropsychologia, 42, 512-523.

Tyler, L., Randall, B., \& Stamatakis, E. (2008). Cortical differentiation for nouns and verbs depends on grammatical markers. Journal of Cognitive Neuroscience, 20, 1381-1389.

Tyler, L.K., Russell, R., Fadili, J., \& Moss, H.E. (2001). The neural representation of nouns and verbs: PET studies. Brain, 124, 1619-1634.

Tyler, L.K., Stamatakis, E.A., Dick, E., Bright, P., Fletcher, P., \& Moss, H.E. (2003). Objects and their actions: evidence for a neurally distributed semantic system. NeuroImage, 18, 542-557. Yokoyama, S., Miyamoto, T., Riera, J., Kim, J., Akitsuki, Y., Iwata, K., Yoshimoto, K., Horie, K., Sato, S., \& Kawashima, R. (2006). Cortical mechanisms involved in the processing of verbs: An fMRI study. Journal of Cognitive Neuroscience, 18, 1304-1313. 
Warburton, E., Wise, R.J.S., Price, C.J., Weiller, C., Hadar, U., Ramsay, S., \& Frackowiak, S.J. (1996). Noun and verb retrieval by normal subjects, Studies with PET. Brain, 119, 159-179.

Zingeser, L.B., \& Berndt, R.S. (1988). Grammatical class and context effects in a case of pure anomia: Implications for models of language processing. Cognitive Neuropsychology, 5, 473-516. 


\section{Figure captions}

Figure 1. Percentage of studies that reported noun- or verb-related activations in any given brain region. Blue numbers refer to simple effects of nouns or verbs versus baseline, whereas red numbers refer to noun-minus-verbs or verbs-minus-nouns direct comparisons. The total number of studies that carried out simple effect analysis in our sample is 20 , whereas the total number of studies that performed noun-verb direct comparisons is 26 . The anterior and posterior portions of the temporal lobe are divided by a line originating from the fronto-ventral corner of Heschl's gyrus and running orthogonally to the main axis of the superior temporal sulcus. 


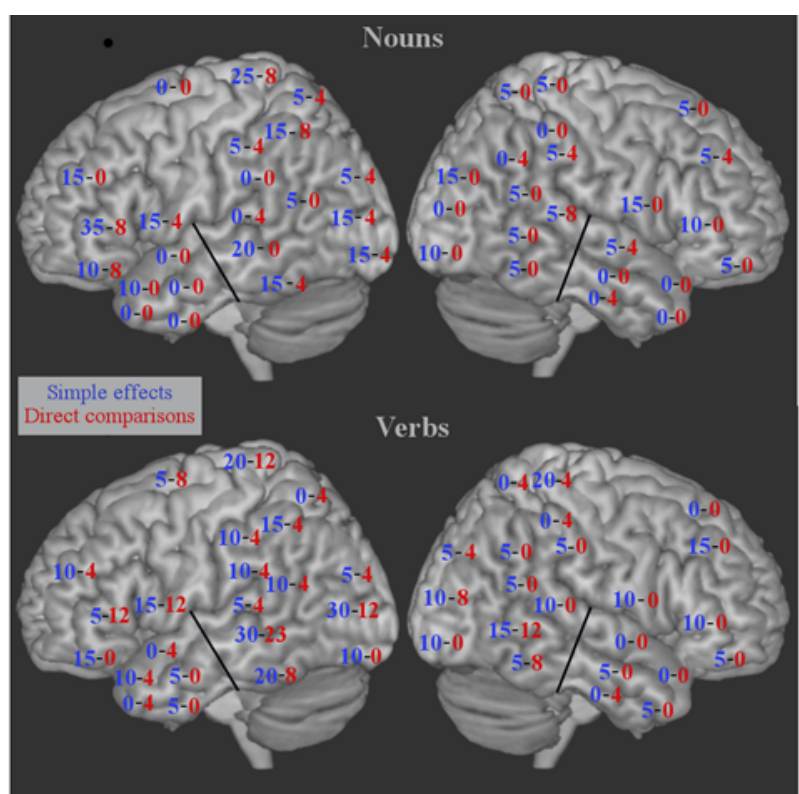




\section{Tables}

Table 1: PET and fMRI studies on nouns and/or verbs using lexical decision as experimental task. Direct comparisons between nouns and verbs are listed in part (a), whereas simple effect analyses are illustrated in part (b)

\begin{tabular}{|c|c|c|c|c|c|c|}
\hline Authors & Technique & Threshold & Design & Baseline & Contrast & Area \\
\hline \multicolumn{7}{|c|}{ (a) Direct noun-verb comparison } \\
\hline \multirow{7}{*}{$\begin{array}{l}\text { Fujimaki et al. } \\
\qquad(1999)\end{array}$} & \multirow{7}{*}{ fMRI } & Cross- & \multirow{7}{*}{ Block } & \multirow{7}{*}{$\begin{array}{l}\text { Line orientation } \\
\text { judgement }\end{array}$} & \multirow{6}{*}{ Nouns-Verbs } & \multirow{5}{*}{$\begin{array}{l}\mathrm{R} \text { and } \mathrm{L} \text { inf. Parietal sulcus, } \mathrm{R} \text { and } \mathrm{L} \text { precentral } \\
\text { sulcus }\end{array}$} \\
\hline & & correlation & & & & \\
\hline & & \multirow{5}{*}{$\begin{array}{l}\text { coefficient, } \\
\text { equivalent to } \\
.005 \\
\text { uncorrected }\end{array}$} & & & & \\
\hline & & & & & & \\
\hline & & & & & & \\
\hline & & & & & & \\
\hline & & & & & Verbs-Nouns & No area \\
\hline \multirow{4}{*}{$\begin{array}{l}\text { Perani et al. } \\
\text { (1999) }\end{array}$} & \multirow{4}{*}{ PET } & .001 & \multirow{4}{*}{ Block } & \multirow[t]{4}{*}{ Letter detection } & & \\
\hline & & & & & Nouns-Verbs & No area \\
\hline & & & & & & L mid. and inf. Frontal gyrus; L sup Parietal lobule; L \\
\hline & & & & & Verbs-Nouns & mid. and inf. Temp gyrus; L inf. Occipital gyrus. \\
\hline
\end{tabular}


Nouns and verbs in the brain

\begin{tabular}{|c|c|c|c|c|c|c|}
\hline Authors & Technique & Threshold & Design & Baseline & Contrast & Area \\
\hline \multirow{3}{*}{ Li et al. (2004) } & \multirow{3}{*}{ fMRI } & .001 & \multirow{3}{*}{ Block } & \multirow{3}{*}{ Fixation } & & \\
\hline & & & & & Nouns-Verbs & Caudate Nucleus \\
\hline & & & & & Verbs-Nouns & No area \\
\hline \multirow[t]{3}{*}{ Thompson et al. } & \multirow{3}{*}{ fMRI } & & Event- & \multirow{3}{*}{ Fixation } & & \\
\hline & & .05 corrected & related & & Nouns-Verbs & No area \\
\hline & & & & & Verbs-Nouns & No area \\
\hline \multirow[t]{3}{*}{ Tyler et al. } & \multirow{3}{*}{ PET } & \multirow{3}{*}{.05 corrected } & \multirow{3}{*}{ Block } & \multirow[t]{3}{*}{ Letter detection } & & \\
\hline & & & & & Nouns-Verbs & No area \\
\hline & & & & & Verbs-Nouns & R substantia nigra \\
\hline \multirow{3}{*}{ Yokoyama et a } & \multirow{3}{*}{ fMRI } & \multirow{3}{*}{.05 corrected } & \multirow{3}{*}{ Block } & \multirow{3}{*}{$\begin{array}{l}\text { Number of } \\
\text { characters } \\
\text { decision }\end{array}$} & & \\
\hline & & & & & Nouns-Verbs & No area \\
\hline & & & & & Verbs-Nouns & No area; L mid. Temporal gyrus (ROI analysis) \\
\hline
\end{tabular}

(b) Simple effect analyses 
Nouns and verbs in the brain

\begin{tabular}{|c|c|c|c|c|c|c|}
\hline Authors & Technique & Threshold & Design & Baseline & Contrast & Area \\
\hline \multirow{10}{*}{$\begin{array}{l}\text { Fujimaki et al. } \\
\text { (1999) }\end{array}$} & \multirow{10}{*}{ fMRI } & Cross- & \multirow{10}{*}{ Block } & & \multirow{7}{*}{ Nouns-baseline } & \\
\hline & & correlation & & & & L Broca's area, L Insula, L ant. Cingulate sulcus, \\
\hline & & coefficient, & & Line orientation & & Precentral sulcus (bilaterally), L Postcentral sulcus, \\
\hline & & equivalent to & & judgement & & bilateral Intraparietal sulcus, L Supramarginal gyrus, \\
\hline & & .005 & & & & bilateral Occipito-Temporal sulcus, R BA 46-47 \\
\hline & & uncorrected & & & & \\
\hline & & & & & & Bilateral Broca's area, Insula and BA 46, bilateral \\
\hline & & & & & \multirow{3}{*}{ Verbs-baseline } & Precentral sulcus, L Postcentral sulcus, bilateral \\
\hline & & & & & & Intraparietal sulcus, L Supramarginal gyrus, \\
\hline & & & & & & Precuneus, bilateral Occipito-temporal sulcus. \\
\hline
\end{tabular}


Nouns and verbs in the brain

\begin{tabular}{|c|c|c|c|c|c|c|}
\hline Authors & Technique & Threshold & Design & Baseline & Contrast & Area \\
\hline Li et al. (2004) & fMRI & $\begin{array}{c}.001 \\
\text { uncorrected }\end{array}$ & $\begin{array}{l}\text { Block } \\
\text { design }\end{array}$ & Fixation & Nouns-baseline & $\begin{array}{l}\text { L and R inf. Frontal gyrus, L and R Postcentral } \\
\text { gyrus, L and R Precentral gyrus, R Sylvian fissure, L } \\
\text { mid-superior Temporal gyrus, R mid Temporal, L inf. } \\
\text { Parietal gyrus, L mid Occipital gyrus, L Fusiform } \\
\text { gyrus, L Cuneus, R and L Cingulate, Thalamus, } \\
\text { Putamen, Caudate Nucleus, Hippocampus, } \\
\text { Lenticular Nucleus, R Cerebellum }\end{array}$ \\
\hline & & & & & Verbs-baseline & $\begin{array}{l}\text { L and R inf. Frontal gyrus, L Precentral gyrus, L } \\
\text { Insula, R Precentral gyrus, R Sylvian fissure, R } \\
\text { medial Frontal gyrus, L mid-superior Temporal } \\
\text { gyrus, R inf. Parietal gyrus, L mid Occipital gyrus, L } \\
\text { sup Occipital gyrus, L and R Fusiform gyrus, L } \\
\text { Cuneus, Thalamus, L and R Cerebellum }\end{array}$ \\
\hline
\end{tabular}


Nouns and verbs in the brain

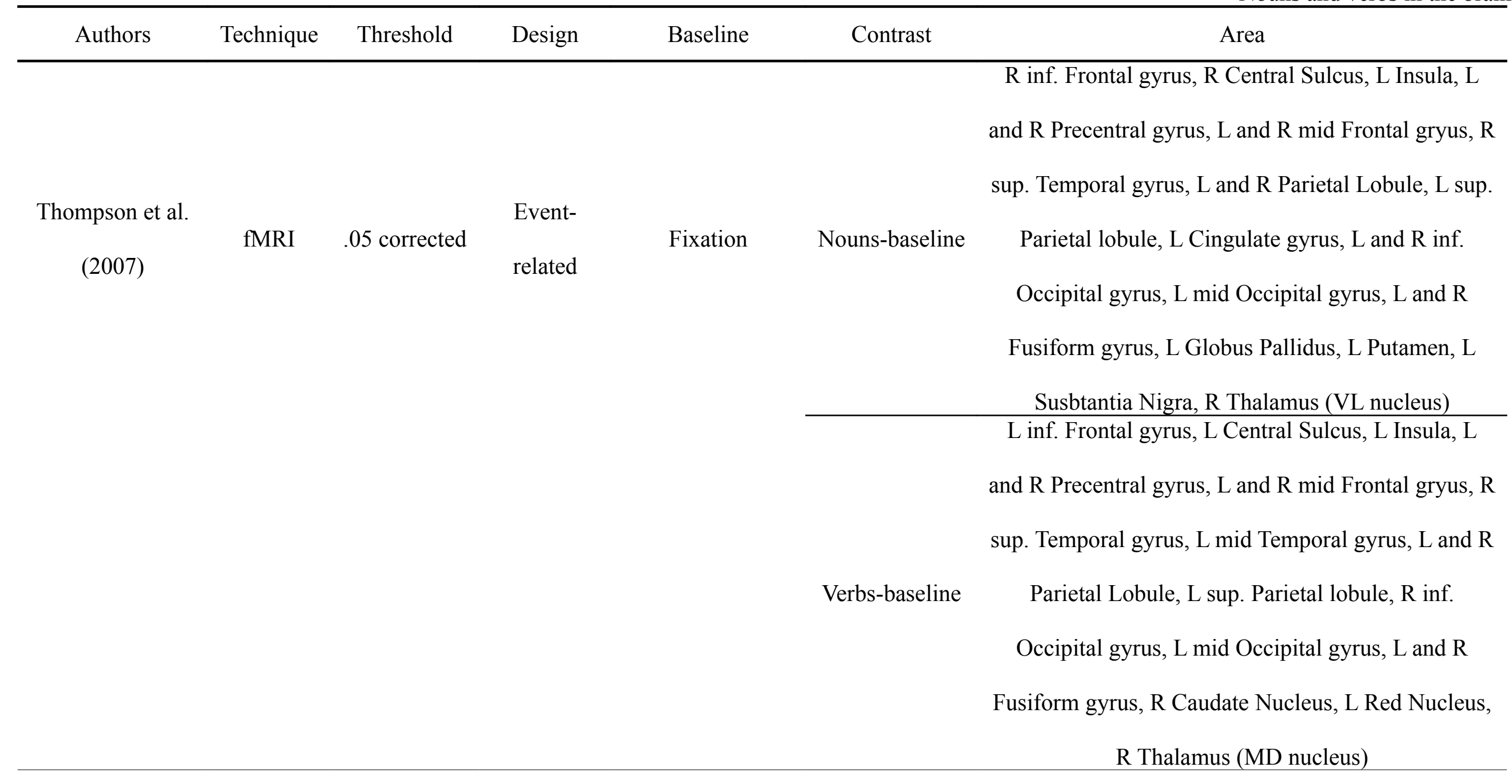


Table 2: PET and fMRI studies on nouns and/or verbs using a semantic experimental task. Direct comparisons between nouns and verbs are listed in part (a), whereas simple effect analyses are illustrated in part (b).

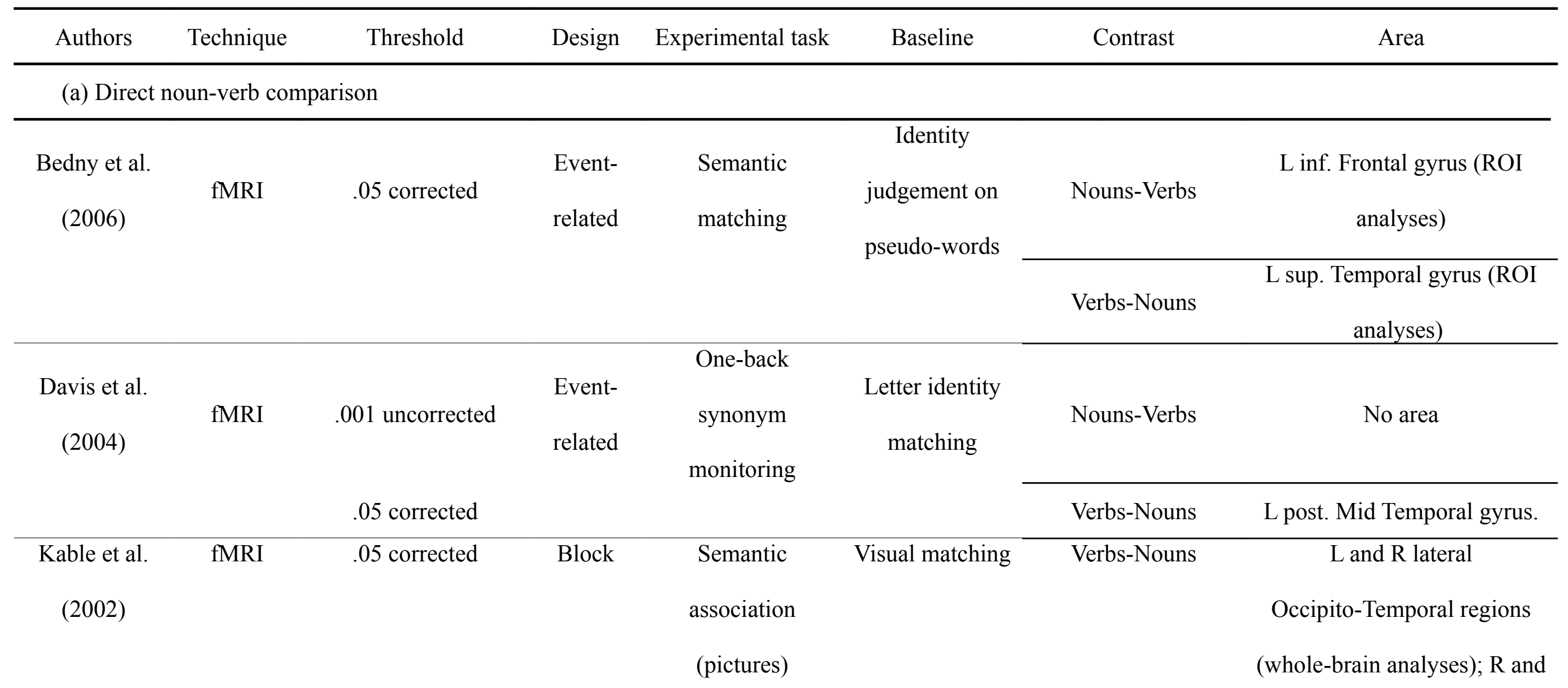


Nouns and verbs in the brain

\begin{tabular}{|c|c|c|c|c|c|c|c|}
\hline Authors & Technique & Threshold & Design & Experimental task & Baseline & Contrast & Area \\
\hline & & & & & & & $\begin{array}{l}\text { L postero-lateral Temporal } \\
\text { region, R and L Occipital } \\
\text { sulcus (ROI analyses). }\end{array}$ \\
\hline & & & & $\begin{array}{l}\text { Semantic } \\
\text { association } \\
\text { (printed words) }\end{array}$ & Visual matching & Verbs-Nouns & $\begin{array}{l}\text { No area (whole-brain } \\
\text { analyses); L postero-lateral } \\
\text { Temporal region (ROI } \\
\text { analyses). }\end{array}$ \\
\hline & fMRI & .001 uncorrected & $\begin{array}{l}\text { Event- } \\
\text { related }\end{array}$ & $\begin{array}{l}\text { Pleasantness } \\
\text { judgement }\end{array}$ & Fixation & $\begin{array}{c}\text { Noun stems-Verb } \\
\text { stems } \\
\end{array}$ & No area \\
\hline & & & & & & $\begin{array}{c}\text { Verb stems-Noun } \\
\text { stems }\end{array}$ & No area \\
\hline & & & & & & $\begin{array}{l}\text { Inflected nouns- } \\
\text { Inflected verbs }\end{array}$ & No area \\
\hline & & & & & & $\begin{array}{l}\text { Inflected verbs- } \\
\text { Inflected nouns }\end{array}$ & L post. mid Temporal gyrus \\
\hline $\begin{array}{c}\text { Palti et al. } \\
\text { (2007) }\end{array}$ & fMRI & .05 uncorrected & Block & $\begin{array}{l}\text { Semantic } \\
\text { judgment }\end{array}$ & $\begin{array}{c}\text { Passive } \\
\text { listening of } \\
\text { words played }\end{array}$ & Verbs-Nouns & L inf. Frontal gyrus \\
\hline
\end{tabular}


Nouns and verbs in the brain

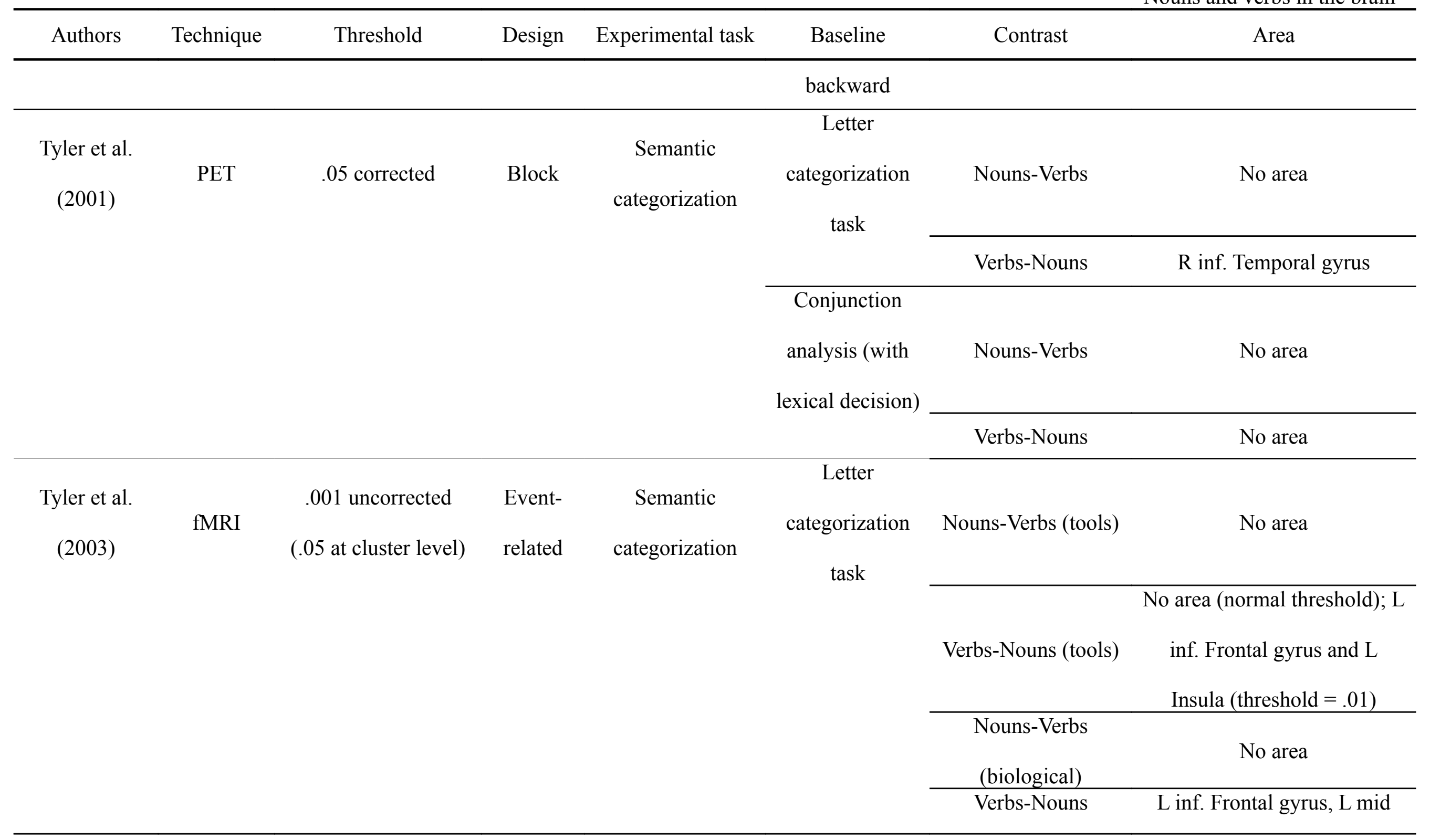


Nouns and verbs in the brain

\begin{tabular}{|c|c|c|c|c|c|c|c|}
\hline Authors & Technique & Threshold & Design & Experimental task & Baseline & Contrast & Area \\
\hline & & & & & & (biological) & Temporal gyrus \\
\hline \multirow[t]{2}{*}{$\begin{array}{c}\text { Tyler et al. } \\
\text { (2004) }\end{array}$} & \multirow[t]{2}{*}{ fMRI } & $\begin{array}{c}.001 \text { uncorrected } \\
\text { (.05 at cluster level) }\end{array}$ & \multirow[t]{2}{*}{$\begin{array}{l}\text { Event- } \\
\text { related }\end{array}$} & \multirow[t]{2}{*}{$\begin{array}{c}\text { Semantic } \\
\text { categorization }\end{array}$} & $\begin{array}{c}\text { Letter } \\
\text { categorization }\end{array}$ & Nouns-Verbs & No area \\
\hline & & & & & & Verbs-Nouns & L inf. Frontal gyrus \\
\hline \multirow[t]{2}{*}{$\begin{array}{c}\text { Tyler et al } \\
(2008)\end{array}$} & \multirow[t]{2}{*}{ fMRI } & $\begin{array}{l}.001 \text { (uncorrected) } \\
\text { (.05 at cluster level) }\end{array}$ & Block & $\begin{array}{l}\text { Pleasantness } \\
\text { judgement }\end{array}$ & Passive viewing & Nouns-verbs & L mid Temporal gyrus \\
\hline & & & & & & Verbs-nouns & No area \\
\hline
\end{tabular}

(b) Simple effect analysis

L inf. Frontal gyrus, R ant.

Cingulate gyrus, L Fusiform

\begin{tabular}{|c|c|c|c|c|c|c|}
\hline & & & & & Letter & \\
\hline & $f M P I$ & .001 uncorrected & Event- & & coterizotion & Verbs(tools)- \\
\hline (2003) & & (.05 at cluster level) & related & categorization & task & baseline \\
\hline
\end{tabular}

and Parahippocampal gyrus,

L Lingual gyrus, $\mathrm{R}$ inf.

Frontal gyrus, R sup. temporal gyrus, $\mathrm{R}$

Cerebellum. 
Nouns and verbs in the brain

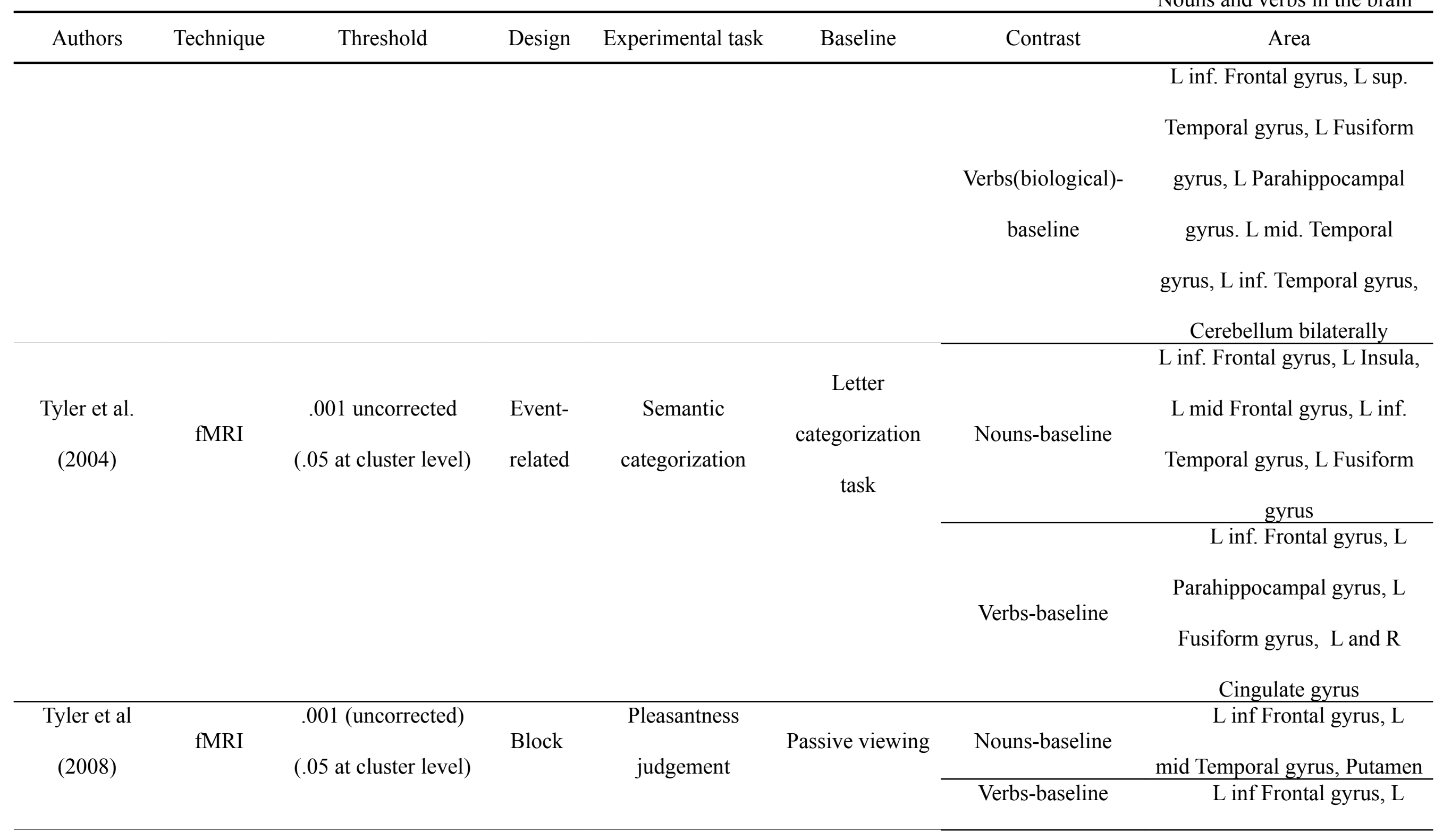


Nouns and verbs in the brain

\begin{tabular}{ccccccc}
\hline Authors & Technique & Threshold & Design & Experimental task & Baseline & Contrast \\
\hline & & & mid Temporal gyrus, \\
& & & Putamen, R Cerebellum \\
\hline
\end{tabular}


Table 3: PET and fMRI studies on nouns and/or verbs using a picture naming experimental task. Direct comparisons between nouns and verbs are listed in part (a), whereas simple effect analyses are illustrated in part (b).

\begin{tabular}{|c|c|c|c|c|c|c|}
\hline Authors & Technique & Threshold & Design & Baseline & Contrast & Area \\
\hline \multicolumn{7}{|c|}{ (a) Direct noun-verb comparison } \\
\hline \multirow{6}{*}{ Berlingeri et al. (2008) } & \multirow{6}{*}{ fMRI } & \multirow{6}{*}{$\begin{array}{c}.001 \\
\text { uncorrected }\end{array}$} & \multirow{6}{*}{ Block } & \multirow{6}{*}{$\begin{array}{l}\text { Forced-choice } \\
\text { figure naming }\end{array}$} & & \\
\hline & & & & & Nouns-Verbs & No area \\
\hline & & & & & \multirow{4}{*}{ Verbs-Nouns } & L inf. Frontal gyrus, L Insula, $\mathrm{R}$ and $\mathrm{L}$ \\
\hline & & & & & & mid. Temporal gyrus, $\mathrm{R}$ inf. Temporal \\
\hline & & & & & & gyrus, R and L post. Parietal gyrus, R \\
\hline & & & & & & and L sup. and mid. Occipital gyrus, \\
\hline \multirow{5}{*}{ Damasio et al. (2001) } & \multirow{4}{*}{ PET } & & \multirow{4}{*}{ Block } & Orientation & \multirow{4}{*}{ Verbs-Nouns } & \\
\hline & & .05 & & iudgement of & & $\mathrm{I}$ and $\mathrm{R}$ mid Temnoral oyrus \\
\hline & & corrected & & juagement or & & L and K mia. Iemporal gyrus \\
\hline & & & & unknown faces & & \\
\hline & \multirow{5}{*}{ fMRI } & \multirow{5}{*}{$.01 \mathrm{FDR}$} & \multirow{5}{*}{ Block } & \multirow{5}{*}{ Fixation } & \multirow{5}{*}{ Nouns (ObjAct)-Verbs } & L inf Parietale lobule, L superior \\
\hline \multirow{4}{*}{ Liljeström et al (2008) } & & & & & & Parietal lobule, L Precuneus, $\mathrm{R}$ mid \\
\hline & & & & & & \\
\hline & & & & & & Frontal gyrus, R superior parietal \\
\hline & & & & & & lobule, R inf. Parietal lobule \\
\hline
\end{tabular}


Nouns and verbs in the brain

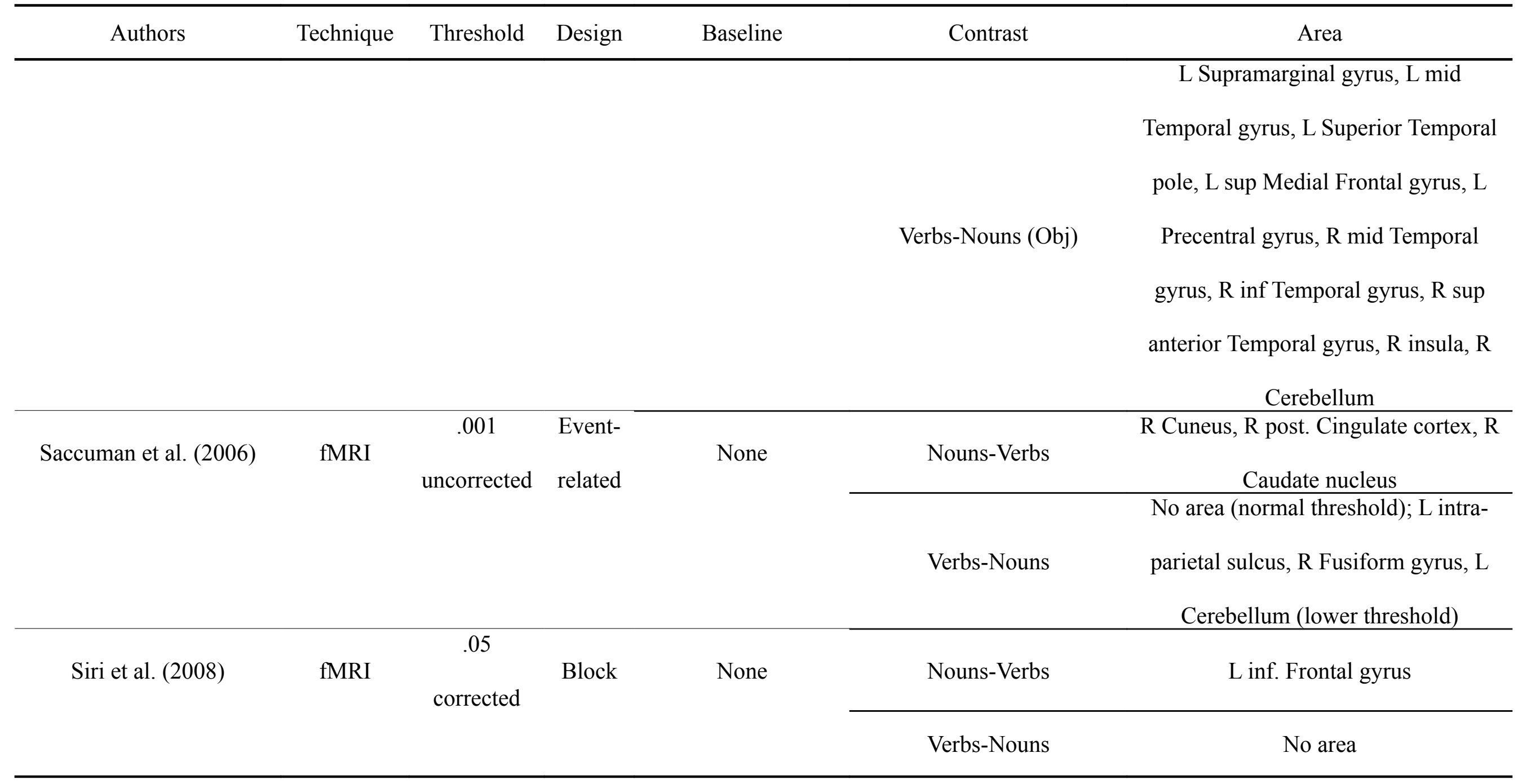

(b) Simple effect analysis 
Nouns and verbs in the brain

\begin{tabular}{|c|c|c|c|c|c|c|}
\hline Authors & Technique & Threshold & Design & Baseline & Contrast & Area \\
\hline Chao et al. (2000) & fMRI & $\begin{array}{c}.001 \\
\text { uncorrected }\end{array}$ & Block & $\begin{array}{l}\text { Passive viewing of } \\
\text { scrambled stimuli }\end{array}$ & Nouns-baseline & $\begin{array}{l}\text { L inf. Frontal gyrus, L Insula, L } \\
\text { ventral Premotor cortex, L post. } \\
\text { Parietal cortex }\end{array}$ \\
\hline Liljeström et al (2008) & fMRI & $.001 \mathrm{FDR}$ & Block & Fixation & Nouns(Obj)-baseline & $\begin{array}{l}\text { L. Precentral gyrus, L SMA, L inf. } \\
\text { Frontal gyrus, L mid. Temporal gyrus, } \\
\text { L Fusiform, L mid. Occipital, L. inf } \\
\text { Occipital, L sup. Parietal lobule, L inf. } \\
\text { Parietal lobule, R inf. Temporal gyrus, } \\
\text { R Fusiform gyrus, R mid Occipital } \\
\text { gyrus, R inf. Occipital gyrus, R sup. } \\
\text { Parietal lobule }\end{array}$ \\
\hline & & & & & Nouns(ObjAct)-baseline & $\begin{array}{l}\text { L inf. Frontal gyrus, L Fusiform, L } \\
\text { mid. Occipital, L sup. Parietal lobule, } \\
\text { L inf. Parietal lobule, R Fusiform } \\
\text { gyrus, R mid Occipital gyrus, R } \\
\text { Precuneus, R sup. Parietal lobule }\end{array}$ \\
\hline
\end{tabular}


Nouns and verbs in the brain

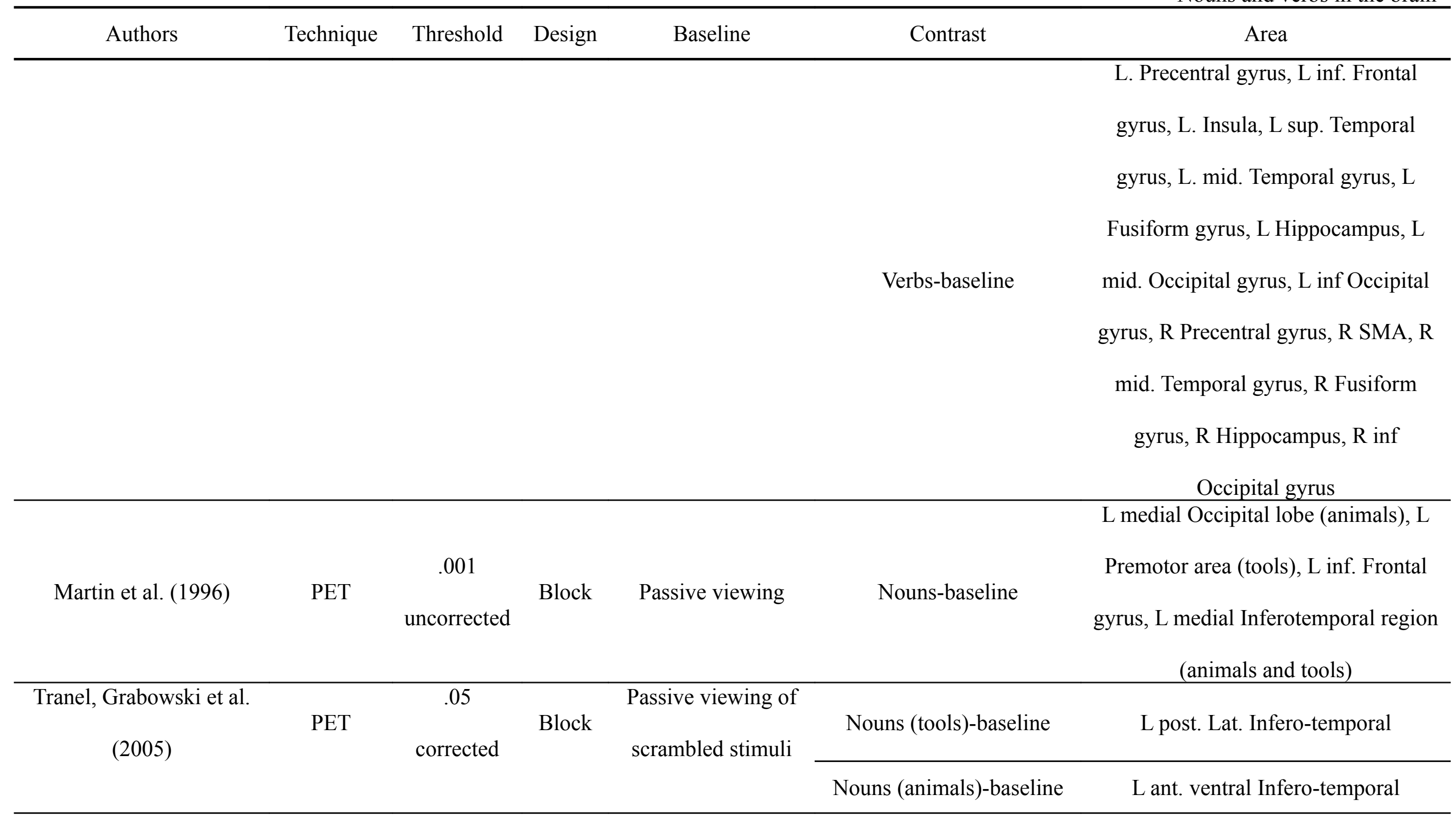


Nouns and verbs in the brain

\begin{tabular}{|c|c|c|c|c|c|c|}
\hline Authors & Technique & Threshold & Design & Baseline & Contrast & Area \\
\hline \multirow{5}{*}{$\begin{array}{l}\text { Tranel, Martin et al. } \\
\qquad(2005)\end{array}$} & \multirow{5}{*}{ PET } & & \multirow{5}{*}{ Block } & Orientation & & \multirow[b]{3}{*}{ L post. ventral Infero-temporal } \\
\hline & & .05 & & & & \\
\hline & & & & judgement on & Nouns(tools)-baseline & \\
\hline & & & & & \multirow[b]{2}{*}{ Verbs-baseline } & L Frontal Operculum, L mid. \\
\hline & & & & & & Temporal, L post. lat. infero-temporal \\
\hline
\end{tabular}


Table 4: PET and fMRI studies on nouns and/or verbs using a morphological experimental task. Direct comparisons between nouns and verbs are listed in part (a), whereas simple effect analyses are illustrated in part (b).

\begin{tabular}{|c|c|c|c|c|c|c|c|}
\hline Authors & Technique & Threshold & Design & Experimental task & Baseline & Contrast & Area \\
\hline \multicolumn{8}{|c|}{ (a) Direct noun-verb comparisons } \\
\hline \multirow[t]{2}{*}{$\begin{array}{l}\text { Berlingeri et al. } \\
\qquad(2008)\end{array}$} & \multirow[t]{2}{*}{ fMRI } & \multirow[t]{2}{*}{.001 uncorrected } & \multirow[t]{2}{*}{ Block } & \multirow[t]{2}{*}{$\begin{array}{l}\text { Grammatical } \\
\text { class switching }\end{array}$} & \multirow[t]{2}{*}{$\begin{array}{l}\text { Forced-choice } \\
\text { figure naming }\end{array}$} & Nouns-Verbs & $\begin{array}{l}\text { L inf. Frontal gyrus, L inf. } \\
\text { Parietal lobule, L Precuneus, L } \\
\text { mid. and sup. Occipital gyrus. }\end{array}$ \\
\hline & & & & & & Verbs-Nouns & $\begin{array}{l}\mathrm{R} \text { and } \mathrm{L} \text { sup. Frontal gyrus, } \mathrm{R} \text { and } \\
\text { L Precentral gyrus, R and L SMA }\end{array}$ \\
\hline \multirow[t]{2}{*}{$\begin{array}{l}\text { Burton et al } \\
\qquad(2009)\end{array}$} & \multirow[t]{2}{*}{ fMRI } & $\begin{array}{l}.05 \text { corrected for } \\
\text { multiple } \\
\text { comparisons }\end{array}$ & Block & \multirow[t]{2}{*}{$\begin{array}{l}\text { Morphological } \\
\text { judgment }\end{array}$} & \multirow[t]{2}{*}{$\begin{array}{c}\text { Tone } \\
\text { discrimination }\end{array}$} & Nouns-Verbs & L inf Frontal gyrus \\
\hline & & & & & & Verbs-Nouns & No area \\
\hline \multirow[t]{2}{*}{$\begin{array}{l}\text { Shapiro et al. } \\
\qquad(2005)\end{array}$} & \multirow[t]{2}{*}{ PET } & \multirow[t]{2}{*}{.001 uncorrected } & \multirow[t]{2}{*}{ Block } & $\begin{array}{l}\text { Word and pseudo- } \\
\text { word inflection }\end{array}$ & $\begin{array}{l}\text { Pseudo-word } \\
\text { reading }\end{array}$ & Nouns-Verbs & $\begin{array}{l}\text { L Fusiform, R mid. sup. Temporal } \\
\text { gyrus, R Insula, R Cerebellum }\end{array}$ \\
\hline & & & & & & Verbs-Nouns & $\begin{array}{l}\text { L sup. Frontal gyrus, L inf. } \\
\text { Frontal gyrus, R cerebellum }\end{array}$ \\
\hline
\end{tabular}


Nouns and verbs in the brain

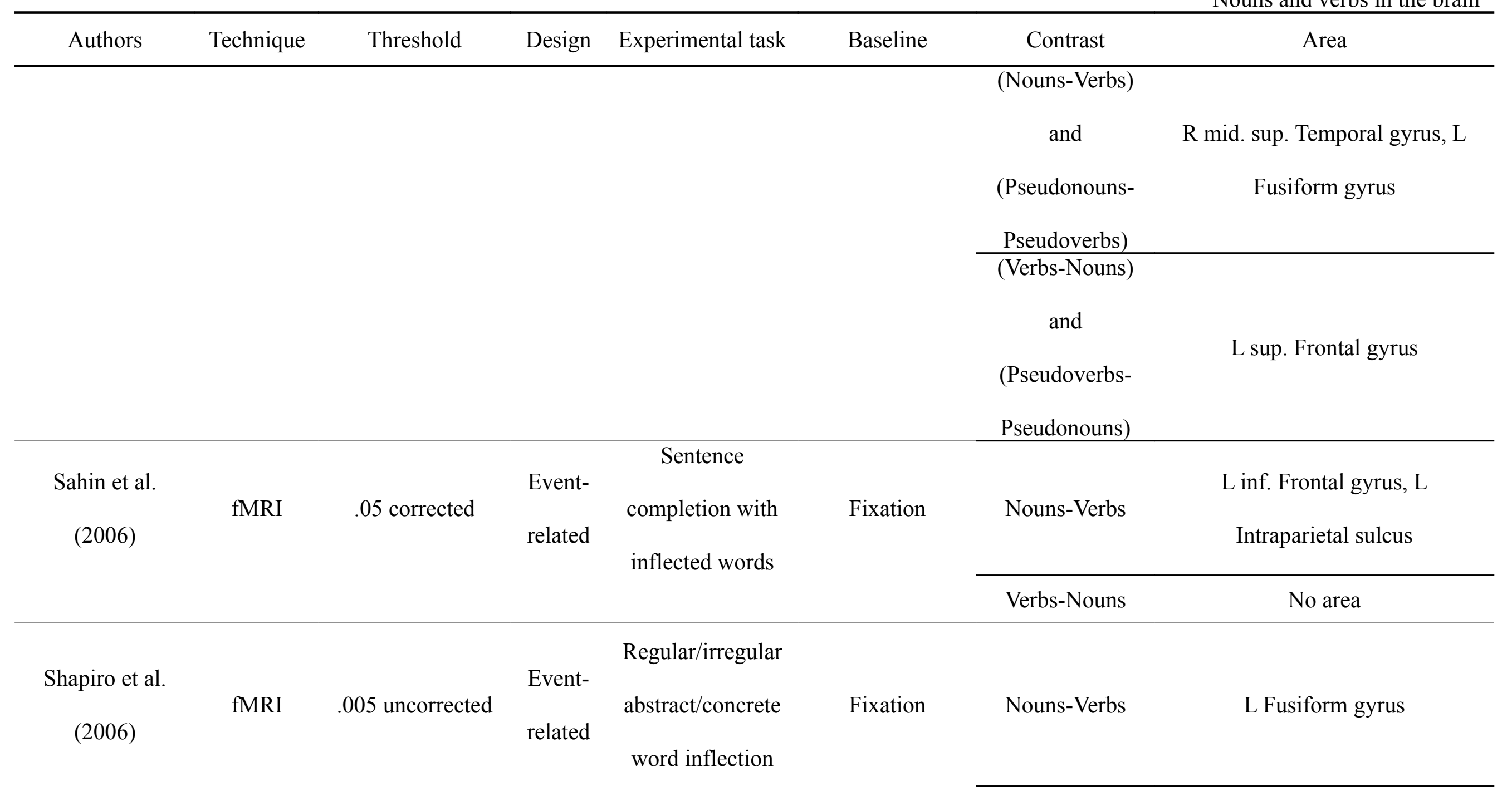


Nouns and verbs in the brain

\begin{tabular}{|c|c|c|c|c|c|c|c|}
\hline Authors & Technique & Threshold & Design & Experimental task & Baseline & Contrast & Area \\
\hline & & & & & & Verbs-Nouns & $\begin{array}{l}\text { L Prefrontal cortex, L sup. } \\
\text { Parietal, L sup. Temporal cortex }\end{array}$ \\
\hline $\begin{array}{l}\text { Palti et al. } \\
\qquad(2007)\end{array}$ & fMRI & .05 uncorrected & Block & $\begin{array}{l}\text { Morphological } \\
\text { judgement }\end{array}$ & $\begin{array}{c}\text { Passive listening } \\
\text { of words played } \\
\text { backwards }\end{array}$ & Verb-Nouns & L Premotor area \\
\hline (b) Simple effe & $\mathrm{t}$ analyses & & & & & & \\
\hline $\begin{array}{l}\text { De Diego } \\
\text { Balaguer et al. } \\
\qquad(2006)\end{array}$ & fMRI & .001 uncorrected & $\begin{array}{l}\text { Event- } \\
\text { related }\end{array}$ & $\begin{array}{l}\text { Word and } \\
\text { pseudoword } \\
\text { inflection task }\end{array}$ & Repetition & Verbs-baseline & $\begin{array}{l}\text { L inf. Frontal gyrus, L } \\
\text { Cerebellum, R Parahippocampal } \\
\text { gyrus, R Sensorimotor cortex } \\
\text { (regular verbs); L inf. Frontal } \\
\text { gyrus, L dorso-lateral Prefrontal } \\
\text { cortex, R sensorimotor cortex, L } \\
\text { Cerebellum (irregular verbs). }\end{array}$ \\
\hline
\end{tabular}


Nouns and verbs in the brain

\begin{tabular}{|c|c|c|c|c|c|c|c|}
\hline Authors & Technique & Threshold & Design & Experimental task & Baseline & Contrast & Area \\
\hline \multirow{18}{*}{$\begin{array}{l}\text { Marangolo et al. } \\
\qquad(2006)\end{array}$} & \multirow{18}{*}{ fMRI } & \multirow{18}{*}{$\begin{array}{l}.01 \text { (.05 corrected } \\
\text { at cluster level) }\end{array}$} & \multirow{18}{*}{ Block } & \multirow{10}{*}{ Derivation } & \multirow{10}{*}{ Repetition } & \multirow{7}{*}{ Nouns-baseline } & $\mathrm{L}$ and $\mathrm{R}$ inf. Frontal gyrus, $\mathrm{L}$ and \\
\hline & & & & & & & R mid Frontal gyrus, L Precental \\
\hline & & & & & & & gyrus, L Insula, L SMA, L mid \\
\hline & & & & & & & Temporal gyrus, $\mathrm{L}$ and $\mathrm{R}$ inf. \\
\hline & & & & & & & Parietal Lobule, L and R Angular \\
\hline & & & & & & & Gyrus, L and R sup. Parietal \\
\hline & & & & & & & lobule, \\
\hline & & & & & & \multirow{3}{*}{ Verbs-baseline } & L inf. Frontal gyrus, L Precentral \\
\hline & & & & & & & \\
\hline & & & & & & & gyrus \\
\hline & & & & \multirow{8}{*}{ Inflection } & \multirow{8}{*}{ Repetition } & & $\mathrm{R}$ ant. And mid Cingulum, $\mathrm{R}$ sup. \\
\hline & & & & & & Nouns-baseline & \\
\hline & & & & & & & Temporal gyrus \\
\hline & & & & & & \multirow{5}{*}{ Verbs-baseline } & L inf. and mid Frontal gyrus, L \\
\hline & & & & & & & Precentral gyrus, L Paracentral \\
\hline & & & & & & & lobule, L SMA, L inf. and sup. \\
\hline & & & & & & & Parietal lobule, L Angular gyrus, \\
\hline & & & & & & & L inf. Temporal gyrus \\
\hline
\end{tabular}


Nouns and verbs in the brain

\begin{tabular}{|c|c|c|c|c|c|c|c|}
\hline Authors & Technique & Threshold & Design & Experimental task & Baseline & Contrast & Area \\
\hline \multirow{5}{*}{$\begin{array}{l}\text { Sahin et al. } \\
\qquad(2006)\end{array}$} & \multirow{5}{*}{ fMRI } & \multirow{5}{*}{.05 corrected } & \multirow{5}{*}{$\begin{array}{l}\text { Event- } \\
\text { related }\end{array}$} & \multirow{5}{*}{$\begin{array}{l}\text { completion with } \\
\text { inflected words }\end{array}$} & \multirow{5}{*}{ Fixation } & \multirow{3}{*}{ Nouns-baseline } & \\
\hline & & & & & & & $\mathrm{L}$ inf. Frontal gyrus, $\mathrm{L}$ ant. Insula, \\
\hline & & & & & & & L SMA, L Intraparietal Sulcus \\
\hline & & & & & & \multirow[b]{2}{*}{ Verbs-baseline } & L inf. Frontal gyrus, L ant. Insula, \\
\hline & & & & & & & L SMA \\
\hline
\end{tabular}


Table 5: PET and fMRI studies on nouns and/or verbs using a fluency experimental task. Direct comparisons between nouns and verbs are listed in part (a), whereas simple effect analyses are illustrated in part (b).

\begin{tabular}{|c|c|c|c|c|c|c|c|}
\hline Authors & Technique & Threshold & Design & Experimental task & Baseline & Contrast & Area \\
\hline \multicolumn{8}{|c|}{ (a) Direct noun-verb comparison } \\
\hline \multirow{3}{*}{$\begin{array}{l}\text { Warburton et al. } \\
\qquad(1996)\end{array}$} & \multirow{3}{*}{ PET } & \multirow{3}{*}{$\begin{array}{l}.005 \\
\text { uncorrected }\end{array}$} & \multirow{3}{*}{ Block } & \multirow{3}{*}{ Semantic fluency } & \multirow{3}{*}{ Rest } & \multirow{3}{*}{ Verb-Nouns } & L inf. Frontal gyrus, L SMA, L \\
\hline & & & & & & & $\begin{array}{l}\text { Precentral sulcus, L inf. Temporal } \\
\text { sulcus, L Temporo-Parietal junction, L }\end{array}$ \\
\hline & & & & & & & inf. Parietal lobe \\
\hline
\end{tabular}

(b) Simple effect analyses

\begin{tabular}{|c|c|c|c|c|c|c|c|}
\hline \multirow[t]{2}{*}{$\begin{array}{c}\text { Frings et al. } \\
\text { (2006) }\end{array}$} & \multirow[t]{2}{*}{ fMRI } & \multirow[t]{2}{*}{$\begin{array}{c}.001 \\
\text { uncorrected }\end{array}$} & \multirow[t]{2}{*}{ Block } & \multirow[t]{2}{*}{ Verb generation } & \multirow[t]{2}{*}{$\begin{array}{l}\text { Verb reading, } \\
\text { Noun reading }\end{array}$} & $\begin{array}{c}\text { Verbs generation- } \\
\text { Verb reading } \\
\end{array}$ & $\begin{array}{c}\text { L inf. Frontal gyrus, L sup. Temporal } \\
\text { gyrus, R Cerebellum }\end{array}$ \\
\hline & & & & & & $\begin{array}{l}\text { Verbs generation- } \\
\text { Noun reading }\end{array}$ & No area \\
\hline
\end{tabular}


Nouns and verbs in the brain

\begin{tabular}{|c|c|c|c|c|c|c|c|}
\hline Authors & Technique & Threshold & Design & Experimental task & Baseline & Contrast & Area \\
\hline $\begin{array}{l}\text { Rowan et al. } \\
\text { (2004) }\end{array}$ & fMRI & $\begin{array}{c}.05 \\
\text { corrected }\end{array}$ & Block & Verb generation & $\begin{array}{l}\text { Passive } \\
\text { listening }\end{array}$ & Verbs-baseline & $\begin{array}{l}\text { L inf. Frontal cortex, L and R Frontal } \\
\text { operculum, L and R Insula, L } \\
\text { Premotor cortex, L SMA, L } \\
\text { Supramarginal gyrus, L inf. Temporal } \\
\text { gyrus, L and R post. Sup. Temporal } \\
\text { cortex, L Putamen, R Cerebellum. }\end{array}$ \\
\hline $\begin{array}{l}\text { Warburton et al. } \\
\qquad \text { (1996) }\end{array}$ & PET & $\begin{array}{c}.005 \\
\text { uncorrected }\end{array}$ & Block & Semantic fluency & Rest & Nouns-baseline & $\begin{array}{l}\text { L inf. Frontal sulcus, L SMA, L and R } \\
\text { Precentral sulcus, L and R Frontal } \\
\text { operculum, L sup. Frontal sulcus, L } \\
\text { ant. Cingulate gyrus, R sup. Temporal } \\
\text { sulcus, L post. Temporal lobe, L } \\
\text { Temporo-Parietal junction, L Caudate } \\
\text { nucleus, L and R Thalamus }\end{array}$ \\
\hline
\end{tabular}


Nouns and verbs in the brain

\begin{tabular}{|c|c|c|c|c|c|c|c|}
\hline Authors & Technique & Threshold & Design & Experimental task & Baseline & Contrast & Area \\
\hline & & & & & & 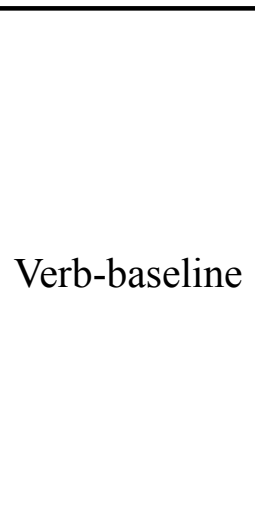 & $\begin{array}{l}\text { L Frontal Operculum, L inf. Frontal } \\
\text { gyrus, R Insula, R SMA, L Precentral } \\
\text { sulcus, R ant. Cingulate gyrus, R sup. } \\
\text { Temporal sulcus, L post. Temporal } \\
\text { lobe, L post. Inf. Parietal lobe, L and } \\
\text { R Caudate nucleus. L and R Thalamus }\end{array}$ \\
\hline
\end{tabular}

